\title{
Nuevos artefactos en el "Nuevo Mundo". La introducción de cultura material alóctona en contextos arqueológicos indígenas en Fuego- Patagonia durante el proceso de contacto (siglos XVI al XX)
}

María J. Saletta* y Dánae Fiore**

Recibido: 13 de marzo de 2018 Aceptado: 21 de agosto de 2018

Palabras clave

Tecnología Categorías culturales Artefactos occidentales Artefactos indígenas Patagonia Tierra del Fuego

New artifacts in the "New World". The introduction of allochthonous material culture in indigenous archaeological contexts in FuegoPatagonia during contact moments $\left(16^{\text {th }}-20^{\text {th }}\right.$ centuries $)$

\footnotetext{
Abstract

This paper analyses the incorporation of European and/or Creole manufacture artefacts to the technological repertoire of Indigenous groups that inhabited Patagonia and Tierra del Fuego between the 16th and 20th centuries, as the result of contact processes with European

* Asociación de Investigaciones Antropológicas (AIA) - CONICET / Universidad Nacional de La Matanza (UNLaM). Bartolomé Mitre 1131, $7^{\circ}$ piso, G (CP C1036AAU), Ciudad Autónoma de Buenos Aires, Argentina. E-mail: adverbiodemodo@gmail.com

** Asociación de Investigaciones Antropológicas (AIA) - CONICET. Bartolomé Mitre 1131, 7º piso, G (CP C1036AAU),

Ciudad Autónoma de Buenos Aires, Argentina. E-mail: danae_fiore@yahoo.es
} 
Keywords

Technology Cultural categories Western artifacts Indigenous artifacts Patagonia Tierra del Fuego groups in Southern South America. To this end, we analysed the published archaeological information of 19,455 artefacts found in 70 post-contact sites. We assessed the types of artefacts, whether they were recycled or not, their presence/absence from sites, and their total and relative frequencies with respect to Indigenous artefacts. We considered that resource availability, Indigenous technologies, logical frameworks and cultural categories, and mobility technologies (pedestrian, equestrian, canoes) were factors involved in their adoption. General results show that allochtonous artefacts were mostly introduced as a source of raw material to manufacture specific local morphologies, and they exhibit variations in artefact types and in their regional frequencies. This may be the result of differential availability, as well as of the presence of different cultural categories and technological practices.

\section{Introducción y objetivos}

En este trabajo analizamos la incorporación de artefactos alóctonos - de manufactura europea y/o criolla - al repertorio tecnológico de los grupos sociales que habitaron Patagonia continental meridional (PCM) y Tierra del Fuego - en las regiones centronorte (TDF C-N), sudeste (TDF SE) y sur (TDF Sur) - entre los siglos XVI y XX en el marco de los procesos de contacto con poblaciones occidentales en ese sector del continente americano. Nos proponemos indagar cómo y qué tipos de artefactos fueron incorporados, si se conservaron sus formas originales o si fueron modificados por los grupos indígenas, para determinar si existieron patrones similares de adopción de dichos artefactos en las diferentes áreas bajo estudio. Consideramos que la adopción de artefactos alóctonos en sociedades cazadoras-recolectoras fue influida por diversos factores: a) la oferta de recursos, caracterizable mediante la disponibilidad de artefactos enteros o fragmentos de ellos, b) las tecnologías indígenas disponibles para poder adoptar, transformar y utilizar los artefactos alóctonos, c) la permeabilidad de cada sociedad a la adopción de nuevos artefactos según sus propias categorías culturales (percepciones, valores, funciones prácticas atribuibles a los recursos de acuerdo a hábitos preexistentes o a otros nuevos) y d) su tecnología de movilidad (pedestre, ecuestre, canoera), que influye en las formas de acceso y capacidad de transporte de nuevos artefactos.

Para dar cuenta de este objetivo se analizó la información publicada sobre contextos arqueológicos de momentos históricos, que dio como resultado un total de 70 sitios localizados desde la margen sur del río Deseado en Santa Cruz hasta el cabo de Hornos en Tierra del Fuego (Saletta, 2015; Saletta y Fiore, 2018b; Saletta y Sacchi, 2019). Aunque estos 70 sitios representan diferentes episodios durante el proceso de contacto y colonización europea y criolla del Fuego-Patagonia, en este primer análisis se los trabaja en conjunto a fin de caracterizar el total de información sobre los sitios indígenas que puedan ser datados y/o adscriptos sobre la base de presencia de materiales europeos entre los siglos XVI y XX. El análisis diacrónico es un objetivo a futuro que, sin embargo, presenta varios desafíos de carácter metodológico. El primero se refiere a que varios sitios publicados carecen de fechados radiocarbónicos y sus adscripciones se realizaron sobre la base de la presencia de elementos europeos (vidrio, metal, etc.) ${ }^{1}$. El segundo, se refiere a la limitación propia del método de datación radiocarbónica cuando se trata de materiales "modernos". De esta manera, a futuro, el análisis diacrónico de los artefactos arqueológicos de sitios indígenas deberá afrontar y resolver estos dos desafíos.

\section{Consideraciones teóricas: continuidades y cambios tecnológicos en el marco de procesos de contacto}

El análisis sobre cómo las sociedades indígenas patagónico-fueguinas interpretaron y reaccionaron a la conquista y ocupación de sus territorios por parte de los europeos 
y, posteriormente, de los estados-nación sudamericanos ha sido abordado por la antropología, la etnohistoria y más recientemente, por la arqueología (Belardi, Carballo Marina, Nuevo Delaunay y De Angelis, 2013; Boschín y Nacuzzi, 1979; Buscaglia, 2015; Carballo Marina, Belardi, Espinosa y Ercolano, 2000-2002; Funari y Senatore, 2015; Gómez Otero, 1989-1990; Goñi, 2000; Goñi y Guráieb, 1996; Manzi, 1996; Martinic y Quiroz, 1989-1990; Martinic y Roehrs, 1991; Nacuzzi, 2005; Nuevo Delaunay, Belardi, Carballo Marina, Saletta y De Angelis, 2017; Palermo, 1986; Saletta, 2015; Saletta y Fiore, 2018a; Saletta y Sacchi, 2019).

En este trabajo el proceso de contacto es abordado desde la arqueología, pero incluyendo en el análisis conceptos teóricos de la antropología. De esta forma, consideramos que el proceso de contacto cultural entre sociedades puede ser explicado adecuadamente si se explicitan los marcos lógicos de las sociedades involucradas (Sahlins, [1977] 2008; Funari y Senatore, 2015). Estos marcos lógicos son los referentes mediante los cuales cada sociedad percibe y clasifica el mundo y su propia realidad "objetiva", interpretando el mundo según sus categorías culturales (Sahlins, [1977] 2008, p. 9) y sus lógicas sociales (Funari y Senatore, 2015, p. 2; Rodríguez-Alegría, Scaramelli y Navas Méndez, 2015, p. 70). Las categorías culturales son significados generales que ordenan la experiencia social humana, usados para referenciar y percibir el mundo. Estas son históricas ya que se construyen y reproducen socialmente a través de la historia de un grupo humano en su contexto social y ambiental. E incluyen, entre otras cosas, las formas socialmente aceptadas de manufactura y uso de artefactos, la distinción entre recursos usables y no-usables, los tabúes que limitan a los recursos no-usables, etc. Por su parte, los marcos lógicos organizan las formas de acción y negociación social (Rodríguez-Alegría et al., 2015, p. 70). Frente a acontecimientos históricos novedosos tales como las situaciones de contacto cultural, los marcos lógicos y las categorías culturales son puestos en riesgo, es decir, se confrontan a hechos previamente no conocidos, donde no habían operado con anterioridad, y donde por lo tanto su funcionamiento habitual no está garantizado (ver caso analizado por Sahlins, [1977] 2008). De acuerdo con Sahlins, el cambio se produce cuando las categorías culturales adquieren nuevos valores funcionales producto de esta puesta en riesgo: en estos casos la estructura se transforma.

Esta línea teórica ya ha sido empleada en otros trabajos sobre arqueología de la subsistencia y la tecnología (Saletta, 2010, 2013, 2015; Saletta y Fiore, 2018a y b). Su utilidad conceptual radica en que toma en cuenta las "condiciones objetivas" del proceso de contacto - disponibilidad espacio-temporal, abundancia relativa y calidad de los recursos- porque sobre ellas actúan los marcos lógicos de cada grupo. Simultáneamente, permite evaluar qué características de los artefactos y/o materias primas podrían haber favorecido o impedido su adopción: maleabilidad, forma, disponibilidad de sucedáneos locales de mejor calidad, entre otras.

Las situaciones de contacto cultural occidentales/indígenas generan no solo presencias de nuevas personas, especies animales y cultura material, sino que también tienen el potencial de tensionar las categorías culturales de ambos grupos (Buscaglia, 2015; Funari y Senatore, 2015; Rodríguez-Alegría, et al., 2015; Saletta y Fiore, 2018b; Senatore et al., 2007; Silliman, 2010; entre otros). En este trabajo nos centraremos en investigar las continuidades y cambios en las prácticas tecnológicas indígenas, analizando el ingreso de tipos de artefactos de manufactura occidental al registro arqueológico cazador-recolector de cada región, con el objeto de inferir y evaluar qué percepciones, valores y características de aquellos operaron en su incorporación al corpus de cultura material tradicional. En particular, se evaluarán: a) la incorporación de nuevos tipos artefactuales sin modificación visible en su morfología (que permite presumir o bien su uso según su función original, o bien su apreciación por características no-utilitarias tales como su aspecto [brillo, color, etc.], su origen exótico, etc.) y b) la reutilización de artefactos como fuentes de materias primas, reciclándolos para manufacturar tipos 
2. En este sentido, del sitio Floridablanca, un enclave español (Buscaglia y Nuviala, 2007), sólo fueron considerados los materiales hallados por fuera del poblado y que las autoras interpretaron como parte de los asentamientos indígenas (Buscaglia, 2009; Buscaglia y Nuviala, 2007).

3. Revistas: Relaciones de la Sociedad Argentina de Antropología, Anales del Instituto de la Patagonia, Magallania, Arqueología, Cuadernos del Instituto Nacional de Antropología y Pensamiento Latinoamericano, previamente existentes (en este también puede incluir aspectos relativos a cuestiones de apreciación no-utilitaria, que quedan enmascaradas por la equifinalidad con cuestiones funcionales). Es en estas prácticas que pueden inferirse algunas de las tensiones y puestas en referencia de las categorías culturales en cada región bajo estudio. Ello permite aportar al conocimiento sobre cómo y por qué las poblaciones indígenas actuaron y qué elementos de sus marcos lógicos operaron en dichos procesos. A su vez, esto permite caracterizar cuestiones relativas a la variabilidad cultural a escala inter-regional, en tanto que es esperable que en cada región se negociarán la puesta en referencia de ciertas categorías culturales, pero no de todas y no de las mismas.

\section{Materiales y métodos}

Se utilizó información arqueológica publicada sobre sitios indígenas asignados temporalmente al post-contacto (siglos XVI al XX) ubicados en Patagonia continental meridional y Tierra del Fuego. Los criterios para identificar un sitio arqueológico como indígena son: a) asignación de los autores de la publicación y/o b) predominio de tipos de artefactos, rasgos y/o estructuras asociadas atribuibles a cazadores-recolectores (Saletta, 2010, 2013, 2015; Saletta y Fiore, 2018b; Saletta y Sacchi, 2019). Se excluyeron del análisis los sitios asociados a colonias o asentamientos colonizadores europeos y/o criollos ${ }^{2}$. Asimismo, se excluyeron del análisis los sondeos o las recolecciones de superficie que no pudieran ser adscriptas con seguridad al periodo bajo análisis: por ende, la mayor parte de los 19.455 artefactos analizados provienen de contextos excavados. El análisis regional de la información publicada reduce las chances de que los procesos de formación del registro arqueológico — culturales y naturales-, que podrían haber actuado en un sitio, generen sesgos sobre el uso de la tecnología a mayor escala. Para ello, se relevaron 170 publicaciones periódicas argentinas y chilenas desde 1930 hasta $2017^{3}$, actas de los Congresos Nacionales de Arqueología Argentina y Jornadas de Arqueología de la Patagonia desde sus respectivos comienzos hasta 2017. Se reconoce como limitación metodológica que la restricción a estas publicaciones implica que es posible que no todos los sitios arqueológicos indígenas publicados estén representados, pero dada la amplia cantidad de información procesada, se infiere que dicha subrepresentación no afectará a las tendencias generales logradas mediante esta base de datos. Esta pesquisa dio como resultado 70 sitios arqueológicos indígenas con fechados o adscripciones asignables a los siglos XVI al XX publicados entre 1973 y 2017 y que se encuentran ubicados desde la margen sur del río Deseado en la provincia argentina de Santa Cruz hasta la costa norte del canal Beagle en la Isla Grande de Tierra del Fuego (ver Tabla 1, Figura 1).

Los datos publicados fueron volcados en una base de datos arqueológica. Esta base de datos relacional a múltiples escalas consta de dos tipos de tablas - por sitio y por tipo de artefacto- que se relacionan entre sí de acuerdo al protocolo diseñado por Fiore (2004) y aplicado en varios trabajos (Fiore, 2002, 2007; Saletta, 2015; Saletta y Fiore, 2018a y b). Las dos tablas de la base de datos se relacionan mediante el número de sitio arqueológico que vincula la información general de un sitio con sus datos sobre tecnología ${ }^{4}$.

\section{Análisis del registro arqueológico}

Los datos arqueológicos publicados sobre sitios indígenas post-contacto fueron analizados cualitativa y cuantitativamente. En el análisis cualitativo se tuvieron en cuenta los procesos de formación del registro arqueológico (Schiffer, 1991): los relativos al comportamiento humano (pautas y técnicas de obtenciónproducción-descarte de materias primas y artefactos, con distintos grados de visibilidad arqueológica), los tipos de materias primas (disponibilidad, abundancia, características, etc.), carácter (perecedero vs. no-perecedero) y los 


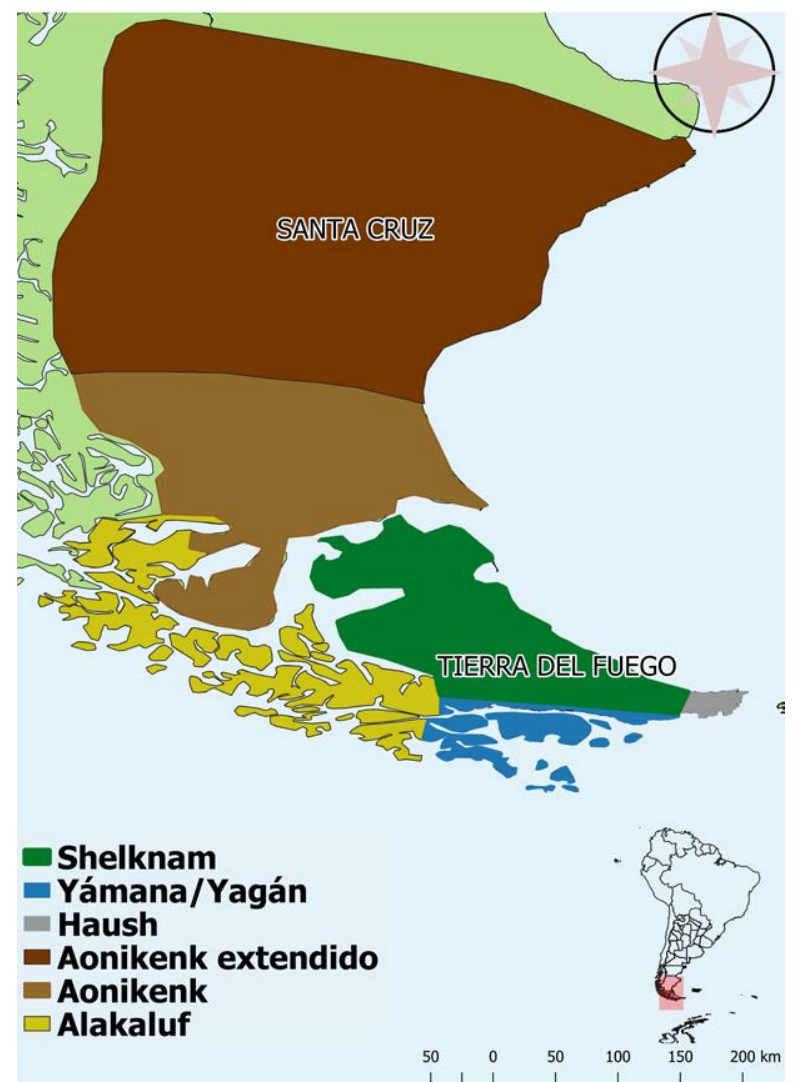

Figura 1. Mapa de Fuego-Patagonia. Nota: Territorio Aonikenk de acuerdo a la información de Coan 1886, Schimid 1860-64, Musters 1871, Beerbohm 1881

post-depositacionales (tafonómicos, antrópicos, etc.). También se consideraron los factores relativos al desarrollo de las técnicas de registro de evidencia empleadas por los arqueólogos/as y los relacionados con los objetivos de investigación propuestos por cada equipo (Schiffer, 1991). Por lo tanto, aunque el registro arqueológico es material, la ausencia de evidencia no es evidencia de ausencia, ya que existen múltiples factores por los cuales ciertos aspectos del comportamiento humano tienen nula o poca preservación. Todos estos aspectos fueron tomados en cuenta en el análisis de los resultados y son retomados en la discusión.

Para el análisis cuantitativo del registro arqueológico se utilizaron tres tipos de cuantificaciones:

» $\mathbf{N}$ de artefactos: es la sumatoria del total de cada tipo de artefacto. Una mayor frecuencia indicaría a priori su producción/obtención/uso más habitual. Se reconoce como limitación su dependencia de la preservación diferencial de las materias primas, de las pautas de conservación de los agentes para con los artefactos, de las tasas diferenciales de pérdida/descarte y de los ambientes en donde eran usados, descartados/perdidos.

» $\mathbf{N}$ de sitios: indica la frecuencia de sitios en los cuales se ha registrado la presencia de un artefacto o materia prima. Se utiliza para medir la dispersión espacial de los artefactos. Su limitación reside en que, como es un conteo nominal, puede llegar a sobre-representar a los artefactos o materias primas menos frecuentes y a subrepresentar a los más frecuentes. 


\begin{tabular}{|c|c|c|c|c|c|}
\hline № Sitio & Nombre & $\begin{array}{l}\text { Asignación temporal publicada } \\
\text { (fechado radiocarbónico y/o } \\
\text { asignación por presencia de } \\
\text { materiales europeos) }\end{array}$ & Sector & $\begin{array}{l}\mathrm{N} \text { de artefactos } \\
\text { mencionados en } \\
\text { publicación }\end{array}$ & Citas \\
\hline 001 & Lancha Pakewaia & $280 \pm 85$ & TFDSUR & 194 & Orquera y Piana, 1993-1994 \\
\hline 002 & Túnel VII & $100 \pm 45$ & TFDSUR & 840 & $\begin{array}{c}\text { Orquera y Piana, 1999; Piana y Orquera, } \\
\text { 1995 }\end{array}$ \\
\hline 003 & Lanashuaia I & $200 \pm 40$ & TFDSUR & 16 & $\begin{array}{c}\text { Piana, Estévez Escalera y Vila Mitjá, } \\
2000 \\
\end{array}$ \\
\hline 004 & Acatushun & s/f post contacto & TFDSUR & 7 (nma) & Piana, Tessone y Zangrando, 2006 \\
\hline 006 & Ea. Harberton (ch 95) & s/f post contacto & TFDSUR & 4 & Piana, Tessone y Zangrando, 2006; \\
\hline 007 & Tres Arroyos 7 & $100 \pm 50$ & TFDC-N & $3(\mathrm{nma})$ & Massone, 2010 \\
\hline 008 & Tres Arroyos 14 A (№89) & $210 \pm 50 \quad 280 \pm 70$ & TFDC-N & 4 & Massone, 2010 \\
\hline 009 & Tres Arroyos 14 B ( $\left.n^{\circ} 88\right)$ & s/f post contacto & TFDC-N & 5 & Massone, 2010 \\
\hline 010 & Ewan 1 & 1905 & TFDC-N & 167 & Mansur y Pique, 2012 \\
\hline 011 & Ewan 2 & 1905 & TFDC-N & 4.481 & Mansur y Pique, 2012 \\
\hline 012 & Puesto Pescador 1 & $335 \pm 35$ & TFDC-N & 2 & $\begin{array}{c}\text { Salemme, Santiago, Suby y Guichón, } \\
2007\end{array}$ \\
\hline 013 & Laguna Sota & post contacto & PCM & 1.150 & Prieto y Schidlowsky, 1992 \\
\hline 014 & Dinamarquero & post contacto & PCM & 1.674 & Martinic y Prieto, $1985-86$ \\
\hline 015 & Cerro Johnny & $350 \pm 90$ & PCM & 1 & Martinic, 1976 \\
\hline 016 & Dungeness 2 & $360 \pm 90$ & PCM & 487 & Massone, 1979 \\
\hline 017 & Pali Aike 2 & $220 \pm 45$ & PCM & 1.084 & Massone e Hidalgo, 1981 \\
\hline 018 & Juni Aike 1 & s/f post contacto & PCM & 33 & Gómez Otero, 1989-90 \\
\hline 019 & Thomas Gould 1 & $250 \pm 150 \quad 470 \pm 170$ & PCM & $5(\mathrm{nma})$ & Massone, 1989-1990 \\
\hline 020 & Sitio El Mulato & s/f post contacto & PCM & $151(\mathrm{nma})$ & Martinic, Prieto y Cárdenas 1995 \\
\hline 021 & Alero Dirección Obligatoria & $390 \pm 110$ & PCM & 45 & $\begin{array}{c}\text { Aschero, Belelli y Goñi 1992-1993; Goñi } \\
\text { y Guraieb, } 1996\end{array}$ \\
\hline 022 & Alero Gorra de Vasco & $200 \mathrm{AP}$ & PCM & 37 & Goñi y Guraieb, 1996 \\
\hline 024 & Punta María 2 & $250300 \pm 100 \mathrm{AP}$ & TFDC-N & 320 & Scheinsohn 1993-1994 \\
\hline 025 & Chacra Pafoy 3 & $332 \pm 39$ & TFDC-N & 1 (nma) & Santiago, Bujalesky y Salemme, 2007 \\
\hline 026 & Foridablanca & s/f post contacto & PCM & $10(\mathrm{nma})$ & Buscaglia y Nuviala, 2007 \\
\hline 027 & Puesto de Yatel & siglo XX & PCM & $83(\mathrm{nma})$ & Nuevo Delaunay, 2007 \\
\hline 028 & Puesto de Quintillán & siglo $X X$ & PCM & $21(\mathrm{nma})$ & Nuevo Delaunay, 2007 \\
\hline 029 & Lago Roca 3 & $170 \pm 30$ & PCM & $4(\mathrm{nma})$ & Franco et al., 1999 \\
\hline 030 & Cueva Don Ariel & $\begin{array}{cc}100 \pm 50 & 200 \pm 100 \\
275 \pm 70 & 300 \pm 50 \\
\end{array}$ & PCM & $3(\mathrm{nma})$ & Nami y Frink, 1999 \\
\hline 031 & Cerro Pampa 2A Parapeto 4 & $170 \pm 40(240)$ & PCM & 681 & $\begin{array}{c}\text { Aragone, 2009; Aragone y Cassiodoro } \\
2009\end{array}$ \\
\hline 032 & Cerro Pampa 2A Parapeto 2 & $310 \pm 40(400)$ & PCM & $3(\mathrm{nma})$ & Ídem anterior \\
\hline 033 & Laguna Cóndor Norte & $220 \pm 41 \quad 187 \pm 41$ & PCM & 236 & Charlín, 2012 \\
\hline 034 & CP (Concentración de Pilas & 260 & PCM & 7 & $\begin{array}{l}\text { Borrazzo, Borrero, Garibotti y Pallo, } \\
2011\end{array}$ \\
\hline 035 & $\begin{array}{l}\text { Yacimiento Campo indio sitio } \\
\qquad \mathrm{Cl} \mathrm{A} 1002\end{array}$ & s/f post contacto & PCM & 1.170 & Carballo Marina, Belardi y Sáenz, 2011 \\
\hline 036 & Puesto Peter & $304 \pm 44$ & PCM & 153 & Carballo Marina, Belardi y Sáenz, 2011 \\
\hline 037 & Ea. El Zorro & $305 \pm 46$ & PCM & o (restos humanos) & Carballo Marina, Belardi y Sáenz, 2011 \\
\hline 038 & Las horquetas & $\geq 200$ & PCM & o (restos humanos) & $\begin{array}{c}\text { Carballo Marina, Belardi, Espinosa y } \\
\text { Ercolano, 2000-2002 }\end{array}$ \\
\hline
\end{tabular}

Tabla 1. Sitios arqueológicos indígenas analizados en el trabajo. Referencias: nma: (número mínimo de artefactos) indica que las publicaciones consultadas informaron la presencia de más artefactos pero sin mencionar su cantidad; nmp: la publicación consultada no incluyó la descripción de artefactos, pero tampoco explicitó si estos estaban ausentes; s/f: sin fechado la publicación no incluyó un fechado radiocarbónico y lo asignó como post-contacto y/o moderno (continúa en la páguina siguiente). 


\begin{tabular}{|c|c|c|c|c|c|}
\hline № Sitio & Nombre & $\begin{array}{l}\text { Asignación temporal publicada } \\
\text { (fechado radiocarbónico y/o } \\
\text { asignación por presencia de } \\
\text { materiales europeos) }\end{array}$ & Sector & $\begin{array}{l}\mathrm{N} \text { de artefactos } \\
\text { mencionados en } \\
\text { publicación }\end{array}$ & Citas \\
\hline 039 & Cañadón del Baile & moderno & PCM & 8 & Ídem anterior \\
\hline 040 & Sitio Markatch Aike 1 & $154 \pm 42 \quad 415 \pm 60$ & PCM & 3 (nma) & Nami y Frink, 1999 \\
\hline 041 & Cañadón Giménez & $\mathrm{s} / \mathrm{f}$ post contacto & PCM & 24 & Moreno y Videla, 2008 \\
\hline 042 & $\mathrm{SAC}_{1}$ & $\begin{array}{ll}352 \pm 40 & 418 \pm 40 \\
389 \pm 40 & 429 \pm 40 \\
\end{array}$ & PCM & 610 & Cassiodoro, Aragone y Re, 2004 \\
\hline 043 & $\mathrm{SAC}_{2}$ & $\mathrm{~s} / \mathrm{f}$ post contacto & PCM & 4 & Cassiodoro, Aragone y Re, 2004 \\
\hline 044 & San Pablo 1 & $290 \pm 70$ & TDFC-N & 23 & Borrero, 1985, Scheinsohn, 1993-94 \\
\hline 046 & San Genaro 2 & $380 \pm 40 \quad 440 \pm 40$ & TDFC-N & 121 & Horwitz, 1995 \\
\hline 047 & San Julio 1 & Moderno & TFDC-N & 12 & Horwitz, Borrero y Casiragui, 1993-1994 \\
\hline 048 & San Julio 2 & $\mathrm{~s} / \mathrm{f}$ post contacto & TFDC-N & 34 & Horwitz, Borrero y Casiragui, 1993-1994 \\
\hline 049 & $\begin{array}{c}\text { Ea. Dos Marías } \\
\text { Florentina LA } 12 \text { (Laguna 12) }\end{array}$ & $310 \pm 60$ & TFDC-N & $3(\mathrm{nma})$ & Massone, 2009; Massone et al., 2003 \\
\hline 050 & Tres Arroyos 1 & 135 & TFDC-N & 4 & Borrero, 1979 \\
\hline 051 & Cabo Vírgenes 8 & $120 \pm 55$ & PCM & 2 (nma) & Borrero y Franco, 2005 \\
\hline 052 & Punta Dungeness 5 & $\mathrm{XVI}$ post quem & PCM & 1 (nma) & Massone, 1984 \\
\hline 053 & Cabo Vírgenes 7 & $160 \pm 40$ & PCM & $5(\mathrm{nma})$ & Borrero y Franco, 2005 \\
\hline 054 & $\mathrm{SAC}_{30}$ & $361 \pm 45$ & PCM & 2 & Cassiodoro y García Guraieb, 2009 \\
\hline 055 & María Luisa 5 (ML 5 ) & $360 \pm 50$ & TDFSE & 13 & Borrero y Lanata, 1988 \\
\hline 056 & Bahía Valentín Sitio 1 (BVS1) & $335 \pm 85$ & TDFSE & $107(\mathrm{nma})$ & Vázquez et al., 2007 \\
\hline 057 & BVS $13_{3}$ (Capa B) & $370 \pm 120$ & TDFSE & 2 (nma) & Tessone et al., 2007 \\
\hline 058 & $\begin{array}{l}\text { Bahía Valentín Sitio } 11 \\
\text { (montículo 1) }\end{array}$ & actual & TDFSE & 147 & Tessone et al., 2007; Vidal, 2011 \\
\hline 059 & El Aleph (Al1) & $330 \pm 50$ & TDFSE & $\mathrm{nmp}$ & Muñoz y Belardi, 2011 \\
\hline 060 & Close to the site 2 (CTS2) & $230 \pm 50$ & TDFSE & 1 & Muñoz y Belardi, 2011 \\
\hline 061 & Juni Aike 3 & $\mathrm{~s} / \mathrm{f}$ post contacto & PCM & 21 & Gómez Otero, 1989-1990 \\
\hline 062 & Cerro Norte XI & $\mathrm{s} / \mathrm{f}$ post contacto & PCM & 100 & Fugassa, Martin y Borrero, 2010 \\
\hline 065 & Kami 7 & $178 \pm 34$ & TDFC-N & 782 & Mansur y De Angelis, 2013 \\
\hline 066 & Cuarto Chorrillo & post contacto & PCM & 150 & Jackson, 1991 \\
\hline 067 & Bajo de la Laguna 2 & $162 \mathrm{AP}$ & PCM & 3.875 & Sacchi, 2013 \\
\hline 068 & Cañadón León 1 & XIX-XX & PCM & 213 & Cirigliano, 2013 \\
\hline 069 & Ea. San Lorenzo & moderno & PCM & 1 & $\begin{array}{c}\text { Carballo y Belardi, } 2007 \text { (en Cirigliano, } \\
\text { 2013) }\end{array}$ \\
\hline 070 & Mala Muerte & siglo XX & PCM & 1 & $\begin{array}{c}\text { Nuevo Delaunay } 2015 \text { (en Nuevo } \\
\text { Delaunay et al., 2017) }\end{array}$ \\
\hline 071 & El Delfín & siglo XX & PCM & 11 & $\begin{array}{c}\text { Nuevo Delaunay } 2015 \text { (en Nuevo } \\
\text { Delaunay et al., 2017) }\end{array}$ \\
\hline 072 & Rancho de Zapa & siglo XX & PCM & 52 & Nuevo Delaunay et al., 2017 \\
\hline 073 & Vega Piaget & siglo XX & PCM & 37 & Nuevo Delaunay et al., 2017 \\
\hline 074 & Hotel Puntal del Lago & siglo XX & PCM & 2 & Nuevo Delaunay et al., 2017 \\
\hline 075 & Mercerat 1 & siglo XX & PCM & 2 & Cirigliano y Vommaro, 2014 \\
\hline \multicolumn{4}{|c|}{ Total artefactos en 70 sitios } & 19.455 (nma) & \\
\hline
\end{tabular}

" N de tipos: es la cantidad de tipos generales de artefactos identificados (determinados a partir de los datos publicados).

La combinación entre el $\mathrm{N}$ de artefactos y el $\mathrm{N}$ de sitios morigera sus respectivas limitaciones dado que las frecuencias de artefactos son evaluadas regionalmente a partir de su registro en sitios. Así se genera un panorama preliminar 
5. Los artefactos de morfologías occidentales manufacturados con materias primas locales fueron registrados en las fuentes históricoetnográficas y sólo se ha registrado un caso arqueológico (Saletta, 2015). Por este motivo no son incluidos en este análisis. acerca de la obtención, manufactura, uso y/o descarte de los artefactos y/o materias primas a escala regional durante el período analizado, por lo cual resulta relevante para nuestras preguntas de investigación.

En adición a la caracterización de los artefactos publicados realizada por sus autores, se realizó una clasificación de los artefactos de acuerdo a su morfología y materia prima: si era local (de Fuego-Patagonia) o alóctona (occidental/industrial). Así se generaron tres posibilidades:

a) artefactos netamente locales: caracterizados por materias primas y morfologías locales, identificables en sitios de momentos pre-contacto;

b) artefactos netamente alóctonos: caracterizados por materias primas y morfologías occidentales e introducidos en contextos cazadores-recolectores (tanto enteros como fragmentos);

c) artefactos mixtos: caracterizados por morfologías locales pero producidos en materias primas occidentales. Se trata del reciclaje de artefactos $-o$ fragmentos de artefactos- con el objeto de producir tipos del repertorio artefactual originario ${ }^{5}$ pero reutilizando materias primas alóctonas.

\section{Área bajo estudio}

A fin de delimitar el área de estudio se empleó información histórico-etnográfica sobre los grupos de Patagonia continental meridional y Tierra del Fuego (Borrero, 2001; Martinic, 1995; Orquera y Piana, [1999] 2015; ver más referencias en Saletta, 2015) (Figura 1). Para Patagonia continental meridional (PCM) se consideró el espacio desde el río Deseado hasta la costa norte del Estrecho de Magallanes, ocupado en tiempos históricos por los Aonikenk, cazadores-recolectores pedestres que luego de la adopción del caballo como tecnología de transporte (principios del siglo XVIII) se convirtieron en ecuestres (Martinic, 1995; Palermo, 1986). Fueron contactados por primera vez en 1520 por Magallanes en la costa de San Julián, Santa Cruz, y en adelante se sucedieron esporádicos contactos durante los siglos XVII y XVIII. A fines del siglo XVIII se fundaron tres establecimientos de diferente carácter en la costa patagónica que podrían haber sido fuente de materias primas alóctonas: Floridablanca (San Julián, en Santa Cruz, 1780-1784, en Senatore et al., 2007), Fuerte San José (península Valdés en Chubut, 1779-1810, en Buscaglia, 2015) y Nuestra Señora del Carmen de Patagones (desembocadura del río Negro, Rio Negro, 1779 - actualidad, Nacuzzi, 2005). Sin embargo, recién en el siglo XIX la presencia europea y criolla aumentó en intensidad y permanencia con la fundación de las primeras poblaciones estables en Punta Arenas (Chile, 1848, Bandieri, 2005) e Isla Pavón (1859, desembocadura río Santa Cruz, Santa Cruz, en Bandieri, 2005).

Tierra del Fuego fue dividida en tres regiones. La primera de ellas, la centro-norte (TDF C-N), abarca la Isla Grande desde la costa sur del estrecho de Magallanes hasta las estribaciones de la cordillera de Darwin en el sur. Estuvo habitada por los Shelknam, contactados por primera vez por Sarmiento de Gamboa en 1580 (Borrero, 2001; Chapman, 1986; Gusinde, [1931] 1982). Estos eran cazadores-recolectores pedestres, con énfasis en el consumo de guanaco. Entre los siglos XVI y XVIII hubo pocos contactos entre estos grupos y viajeros europeos y criollos (Saletta, 2013, 2015; Saletta y Fiore, 2018b). No fue hasta finales del siglo XIX que las estancias laneras se establecieron y que los estados chileno y argentino fundaron algunos poblados (Martinic, 1973). La segunda región se encuentra al sudeste de la Isla Grande (TDF SE) y ocupa toda la península Mitre. Sus habitantes se encontraron con europeos por primera vez en bahía Buen Suceso en 1619 (Saletta, 2015). También eran cazadores-recolectores pedestres — similares a los 
Shelk'nam - con una dieta más orientada al consumo de recursos marinos. Durante el siglo XVII hasta la mitad del siglo XIX los contactos con europeos fueron regulares y no fue hasta finales del siglo XIX, que se estableció una subprefectura en Buen Suceso, cuando comenzó un contacto algo más regular (Fiore, 2004; Saletta, 2015; Saletta y Fiore, 2018a y b). TDF Sur es la última región y comprende el canal Beagle y el archipiélago sur de Tierra del Fuego. Fue habitada por los Yámana/Yagán, cazadores-recolectores canoeros especializados en la captura de recursos marinos (Orquera y Piana, [1999] 2015). Su primer contacto con europeos fue en la bahía Orange en 1624. Durante los siglos subsiguientes no fueron regularmente contactados, sino hasta principios del siglo XIX con el arribo de los balleneros, aumentando la frecuencia de los encuentros (Orquera y Piana, [1999] 2015). En 1869 se asentó en la bahía de Ushuaia la Misión anglicana, convirtiéndose en el primer asentamiento en este sector hasta que 1884 se fundó la subprefectura (Bridges, [1948] 2005, entre otros).

\section{Análisis del caso}

La información publicada arrojó datos sobre 70 sitios arqueológicos indígenas con dataciones y/o materiales asignables al período de contacto ubicados en las siguientes regiones arqueológicas (Tabla 1 ):

4. Patagonia centro-meridional (PCM, Aonikenk): 44 sitios

5. Tierra del Fuego, región centro-norte (TDF C-N, Shelk’nam): 16 sitios

6. Tierra del Fuego, región sudeste, península Mitre (TDF SE, Haush): 5 sitios

7. Tierra del Fuego, región sur, canal Beagle-cabo de Hornos (TDF Sur, Yámana/ Yagán): 5 sitios

\section{Análisis de sitios con artefactos netamente locales, alóctonos y mixtos}

Con el propósito de contextualizar los casos de estudio, presentamos aquí los datos histórico-etnográficos sobre las formas de ingreso de los artefactos alóctonos a lo largo del período de contacto. Estos datos provienen de la lectura de 208 fuentes escritas por 100 autores entre los siglos XVI y XX (Saletta, 2015; Saletta y Fiore, 2018a). Los criterios de selección y evaluación crítica de las fuentes incluyeron: que hayan sido escritas por observadores directos visitantes de las regiones bajo estudio (es decir, "fuentes de primera mano"), la duración de la visita de la región, los propósitos del viaje, el idioma de comunicación con los indígenas, los conceptos y valores explícitos e implícitos en el texto, la presencia/ausencia de contradicciones internas dentro del texto, etc. (Fiore, 2002, 2004; Saletta, 2015). A su vez, la comparación sistemática entre fuentes escritas histórico-etnográficas incluyó: a) la comparación entre distintas ediciones de un mismo texto (en busca de inconsistencias, adiciones o eliminaciones de información) y b) la comparación entre distintos textos del mismo autor y de distintos autores, para evaluar si sus contenidos se corroboran, complementan y/o contradicen (Fiore, 2002, 2004; Saletta, 2015). A partir de estos análisis sistemáticos, se registraron formas de interacción entre grupos indígenas y occidentales (viajeros, militares, misioneros, etnógrafos, comerciantes, estancieros, etc.) que incluyeron la circulación de bienes occidentales al interior de los grupos, mediante trueque, regalos y/o robo/hurto, así como el hallazgo fortuito o los despojos de naufragios. Por cuestiones de espacio, no se detallan aquí las circunstancias de producción de cada texto, sino que se sintetiza solo la información obtenida acerca de los mencionados procesos de interacción, incluyendo solamente aquella que, luego de las evaluaciones arriba mencionadas, resultó proveer datos de mayor precisión, confiabilidad y relevancia para el tema planteado (Tabla 
2). Estos aspectos sí han sido tomados en cuenta en otros trabajos (Fiore, 2002, 2004; Saletta, 2013, 2015; Saletta y Fiore, 2018b) demostrando su potencial en el análisis conjunto de ambas líneas de evidencia.

El intercambio fue la estrategia privilegiada de acceso a nuevos artefactos, ya que fue registrado por la mayoría de los autores de todas las áreas ( $\mathrm{n}=52$ observadores), el regalo fue la segunda forma de obtención $(\mathrm{n}=29)$ y el robo/hurto fue el menos informado $(\mathrm{n}=8)$, lo que señalaría que esta no constituyó una manera habitual de obtención de materias primas por parte de los nativos. Esto último constituye un interesante aporte a la deconstrucción de mitos relativos al "vandalismo" atribuido prejuiciosamente a los pobladores originarios de Fuego-Patagonia, mitos que no parecen fundamentarse siquiera en los textos escritos por los propios autores occidentales. La cantidad de observadores que registraron estrategias de obtención de recursos tecnológicos alóctonos (16 en PMC, 12 en TDF CN-TDF SE y 29 en TDF Sur) indica que estos registros fueron similares a escala inter-regional (mayores en TDF Sur), aumentando así su confiabilidad y su potencial para efectuar comparaciones.

\section{Artefactos y sitios: materias primas y morfologías a escala regional}

En esta sección se presenta la frecuencia de hallazgo de artefactos netamente alóctonos, netamente locales o mixtos, por sitio, distinguiéndolos de acuerdo a las variables bajo análisis: materias primas y morfologías (Figura 2).

En PCM existía una cuasiparidad entre los locus de uso/depositación de artefactos de materias primas locales y alóctonas y aquellos donde solamente se registran las locales, pero con una importante frecuencia de sitios con materiales solamente alóctonos. En TDF C-N, en cambio, se observa una llamativa paridad entre los tres grupos de sitios. En los restantes sitios, los $\mathrm{N}$ son bajos por lo cual no se identifican patrones precisos. En TDF SE los sitios con materias primas alóctonas y locales son algo más frecuentes. La baja cantidad de sitios post-contacto y de sitios con materias primas alóctonas es llamativa teniendo en cuenta que península Mitre fue un espacio privilegiado de encuentros entre europeo/criollos y fueguinos (Belza, 1974; Saletta, 2015, 2017) y se encuentra, además, favorecida por la llegada de corrientes marinas que arrojan a sus costas despojos de naufragios (una fuente alternativa de materias primas alóctonas), los que ocurrieron muy frecuentemente en esa zona $(n=61$, Saletta, 2015). Esta baja cantidad de sitios también podría ser resultado de que es difícil acceder a ella y/o debido a que los intereses de investigación se focalizaron más en otros períodos de la secuencia arqueológica (Vázquez, Zangrando, Tessone y Ceraso, 2011; Vázquez, Zangrando, Tessone, Ceraso y Sosa, 2007;

6. Nuevas investigaciones están considerando el momento post-contacto, por lo que en el futuro habrán nuevos datos (F. Zangrando, comunicación personal, febrero 2018). Vidal, 2011) ${ }^{6}$. Finalmente, los cinco sitios de TDF Sur muestran paridad entre los casos que tienen ambas clases de materias primas con los que sólo presentan materias primas alóctonas, mientras que hay un sitio que sólo tiene artefactos en materias primas locales. También en este caso es posible que hayan actuado sesgos de investigación, favorables a entender el proceso de poblamiento de este sector, que expliquen la baja cantidad de sitios post-contacto publicados (Orquera y Piana, 1999).

Se destaca que el $52 \%$ de los 70 sitios analizados en este trabajo tienen presencia de artefactos en materias primas alóctonas, lo que señala que la ausencia de dichos materiales no puede ser utilizada de manera fiable como un indicador cronológico de sitios pre-contacto. La datación permite tener la certeza de la adscripción temporal de sitios que no presenten materiales europeos (Nuevo Delaunay et al., 2017; Saletta, 2010, 2013; Saletta y Fiore, 2018a; Saletta y Sacchi, 2019; Vázquez et al., 2011).

Notablemente, todas las regiones bajo estudio presentan un comportamiento similar en cuanto a la frecuencia de sitios con artefactos en materias primas alóctonas: es más 
$\square$ PC $\square$ TDF centro-norte $\square$ TDF sur $\square$ TDF sudeste

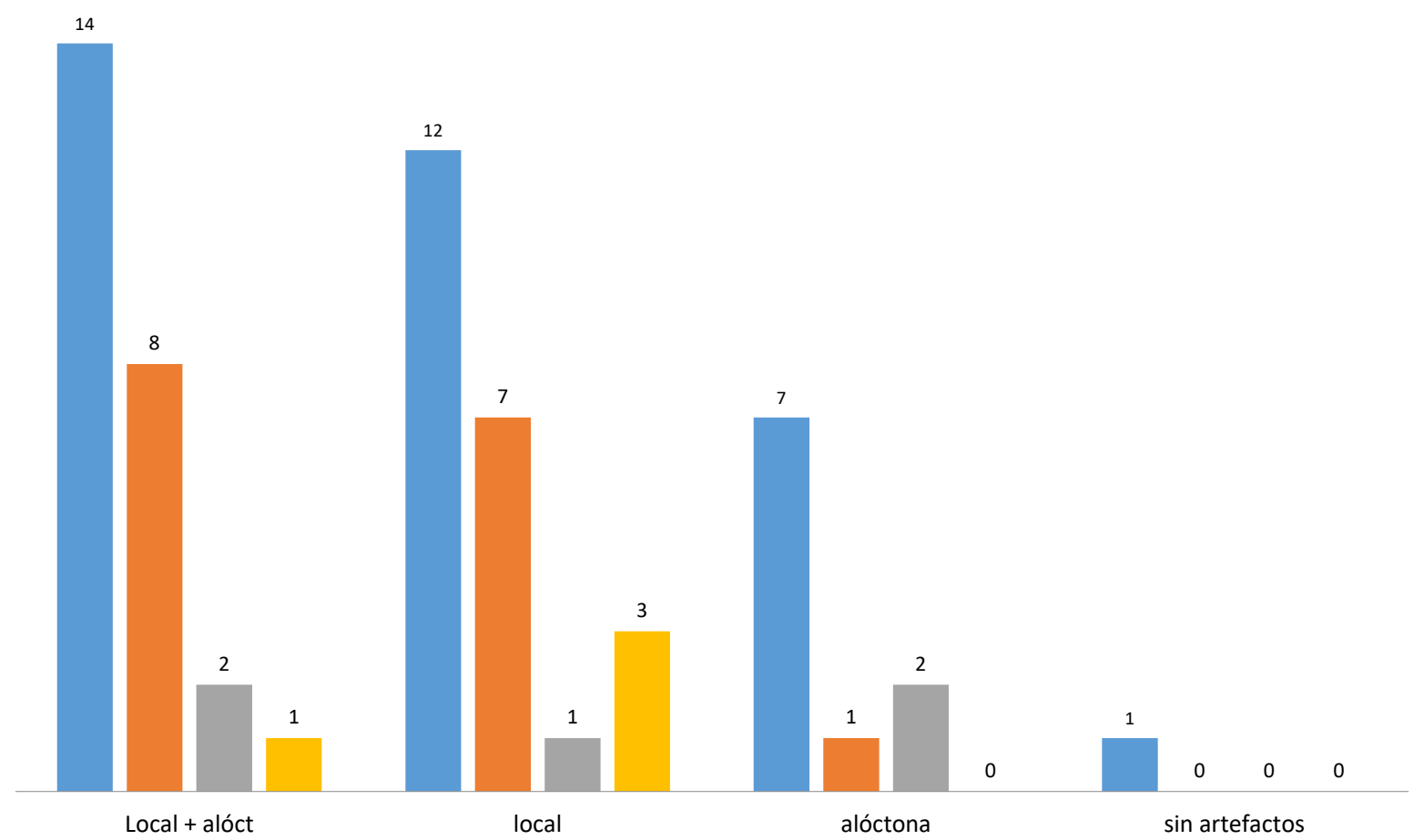

Figura 2. Cantidad de sitios con artefactos de materias primas locales y/o introducidas, por región.

\begin{tabular}{|l|c|c|c|}
\hline $\begin{array}{l}\text { Registro de N de autores desde siglo } \\
\text { XVI al XX }\end{array}$ & trueque & robo/hurto & regalo \\
\hline PCM & 14 & 2 & 6 \\
TDF centro-norte/ sudeste & 10 & 2 & 7 \\
TDF sur & 28 & 4 & 16 \\
\hline
\end{tabular}

Tabla 2. Cantidad de observadores en el registro histórico-etnográfico.

frecuente hallarlos asociados a artefactos en materias primas locales (PCM 31\% de 44 sitios, TDF C-N 47\% de 16 sitios, TDF SE y Sur 40\% de cinco sitios, respectivamente). En tanto, los sitios que sólo presentan artefactos en materias primas europeas son menos frecuentes en todas las áreas bajo estudio (PCM 16\%, TDF C-N 6\%, TDF SE $20 \%$ y TDF Sur $40 \%$ ), aunque el N de sitios de PCM es más alto que en las restantes regiones, lo que podría indicar una mayor disponibilidad y abundancia relativa en esta región. La relativa paridad de sitios con ambos tipos de materias primas para todas las regiones sugiere que los grupos que las habitaban habrían circulado en el espacio de sus territorios transportando efectivamente materiales alóctonos sumados a los locales.

En cuanto a qué materias primas han sido registradas en cada una de las regiones, en la Tabla 3 se observa que PCM es la única región en donde están presentes 13 de las 14 materias primas registradas ${ }^{7}$ : seis tipos locales y siete tipos alóctonas. TDF C-N le sigue en frecuencia con muchos menos tipos de materias primas $(n=7)$ : tres locales y cuatro alóctonas. En TDF SE se observa la menor cantidad de tipos de materias 
8. Sitios SAC 30 (Sierra Colorada, Santa Cruz), donde se hallaron dos láminas de hierro, y Cerro Norte XI con 100 cuentas de vidrio europeas (citas en Tabla 1).
9. En Túnel VII las marcas de corte con instrumentos de metal en algunos elementos óseos constituyen una evidencia indirecta del uso de artefactos de origen industrial pero de los cuales no puede determinarse la morfología (Orquera y Piana, 1995). Algo similar ocurre con los fragmentos de hierro hallados en Lancha Pakewaia, cuyas morfologías no fue posible determinar (Orquera y Piana, 1993-1994). primas $(n=5)$ : tres alóctonas y dos locales. En TDF Sur hay seis tipos de materias primas representadas: cuatro alóctonas y tres locales. Todo indicaría que el hecho de que las materias primas alóctonas estén más representadas en el registro arqueológico se debe a una conservación diferencial de algunas de ellas (como los metales, el vidrio, la loza, la pasta), lo que redunda en una mayor cantidad de tipos recuperados arqueológicamente. Hay cuatro tipos de materias primas que están presentes en todas las regiones bajo estudio: dos locales (lítico y óseo) y dos alóctonas (hierro y vidrio), indicando su circulación/uso/descarte en todos los territorios. A su vez, estas también son algunas de las materias primas que presentan mejor conservación en las regiones bajo estudio.

En el caso de las morfologías, clasificadas como locales o alóctonas (independientemente de la materia prima), predominan los sitios con formas locales pero en distintas proporciones (Figura 3). En PCM se registra una cuasiparidad entre sitios con artefactos de morfologías locales $(n=16)$ y sitios con artefactos de ambas morfologías $(n=15)$. Solo dos sitios registran exclusivamente artefactos en morfologías alóctonas ${ }^{8}$. En TDF C-N la tendencia es mucho más clara: de los 16 sitios, en 11 de ellos se encontraron artefactos en morfologías locales, mientras que en cuatro sitios fueron hallados artefactos de ambas morfologías y no hay ningún sitio hasta ahora publicado con artefactos solo en morfologías alóctonas. En TDF SE se mantiene la misma tendencia: un predominio de los sitios con artefactos en formas locales $(n=3)$ y un sitio con artefactos en ambos tipos de morfologías $(n=1)$, sin sitios que presenten artefactos sólo en morfologías alóctonas (sí hay un caso en el que la tecnología hallada en el sitio no fue publicada: El Aleph 1, ver Tabla 2). TDF Sur exhibe también una tendencia de predominio de sitios con morfologías locales $(n=3)$, sólo hay un sitio con artefactos en morfologías alóctonas (los dos enterratorios de Acatushun).

Al evaluar estos datos a escala interregional, resulta notorio que PCM se diferencia de TDF en su relativa paridad entre sitios con artefactos en morfologías locales y sitios con morfologías locales y alóctonas. A ello se suma que en PCM hay dos sitios que sólo tienen artefactos de formas alóctonas, algo que no se aprecia en ninguna de las tres regiones de TDF. Estas diferencias permiten inferir varios aspectos. El primero, la mayor disponibilidad de artefactos alóctonos en la parte continental, producto del intercambio con europeos, criollos u otros grupos indígenas. El segundo, la presencia de una tecnología de transporte - el caballo- que permitió incorporar estos nuevos artefactos conservando los tradicionales. Ello implicaría que los grupos patagónicos continentales tenían una plasticidad para negociar ciertas categorías culturales tecnológicas que implicaban cambios y aumentos en el repertorio artefactual y, por ende, un cambio en los valores de sus categorías tecnológicas. El tercer aspecto tiene que ver con que los grupos de TDF - tanto de C-N, como de SE y Sur- parecen haber sido más reticentes a la incorporación de artefactos de morfologías novedosas lo que podría relacionarse con constricciones de movilidad para los pedestres e incluso para los canoeros, pero también con las funcionalidades de esos nuevos artefactos en contextos de cazadores-recolectores de alta movilidad. Es cierto también que el número bajo de casos analizados para el sur y sureste de Tierra del Fuego impide que las tendencias halladas sean estadísticamente significativas, esto último queda reforzado por el hecho que, de las tres regiones bajo análisis de Tierra del Fuego, la menos "conservadora" sea la que más casos tiene (TDF C-N). Nuevas investigaciones abocadas a indagar sobre este momento podrán confirmar o cambiar las tendencias señaladas.

Los artefactos de morfologías autóctonas más frecuentes y/o diagnósticas incluyen: lascas, raspadores, puntas de proyectil, raederas, raspadores, punzones, puntas de arpón y tiestos de cerámica (ver detalles en Saletta, 2015). Los artefactos de morfologías alóctonas más frecuentes y/o diagnósticas incluyen: cuentas, cazuelas, botellas, clavos, porrones, discos, leznas, formones, botones, cuchillos, tenedores, 


\begin{tabular}{|c|c|c|c|c|c|c|}
\hline & Materia Prima & PCM & TDF C-N & TDF SE & $\begin{array}{l}\text { TDF } \\
\text { Sur }\end{array}$ & $\begin{array}{l}\mathrm{N} \text { regiones que } \\
\text { comparten esta }\end{array}$ \\
\hline$\overline{\widetilde{J}}$ & $\begin{array}{l}\text { Cerámica indígena } \\
\text { Cuero } \\
\text { Lítico } \\
\text { Minerales (pigmentos) } \\
\text { Malacológica } \\
\text { Óseo }\end{array}$ & $\begin{array}{l}x \\
x \\
x \\
x \\
x \\
x\end{array}$ & $\begin{array}{l}x \\
x\end{array}$ & 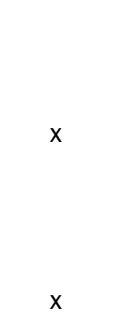 & $x$ & $\begin{array}{l}1 \\
2 \\
4 \\
3 \\
3 \\
4\end{array}$ \\
\hline $\begin{array}{l}\overline{\widetilde{J}} \\
\frac{\bar{U}}{\tilde{U}} \\
. \bar{U} \\
0\end{array}$ & $\begin{array}{l}\text { Bronce } \\
\text { Cobre } \\
\text { Tela } \\
\text { Hierro } \\
\text { Loza } \\
\text { Pasta } \\
\text { Plata } \\
\text { Vidrio } \\
\text { Indet-europeo }\end{array}$ & $\begin{array}{l}x \\
x \\
x \\
x \\
x\end{array}$ & $\begin{array}{l}x \\
x \\
x\end{array}$ & $\begin{array}{l}x \\
x\end{array}$ & $\begin{array}{l}x \\
x\end{array}$ & $\begin{array}{l}1 \\
2 \\
1 \\
4 \\
3 \\
1 \\
1 \\
4 \\
2\end{array}$ \\
\hline Inde & erminado & $x$ & & & & 1 \\
\hline NMA & & $x$ & $x$ & $x$ & & 3 \\
\hline $\begin{array}{l}\mathrm{N} \text { tip } \\
\text { regió }\end{array}$ & $\begin{array}{l}\text { os materias primas } x \\
n \text { (sin indet.) }\end{array}$ & 13 & 7 & 5 & 6 & \\
\hline$N$ sit & & 44 & 16 & 5 & 5 & \\
\hline
\end{tabular}

Tabla 3. Materias primas registradas arqueológicamente en cada región.

zunchos, e incluso una pieza textil (ver detalles en Saletta, 2015). Al considerar los tipos de morfologías autóctonas y alóctonas resultan notorias las diferencias halladas a escala interregional (Tabla 4). En PCM se registra una cuasiparidad entre tipos de artefactos de morfología local y de morfología alóctona, mientras que en el resto de las regiones de TDF predominan netamente los tipos de artefactos de morfología local (Tabla 4). Ello podría en parte ser resultado de las diferencias en el tamaño de las respectivas muestras ( $\mathrm{N}$ de sitios de cada región), pero si la tendencia solamente fuese un producto de dichos sesgos, éstos deberían haber afectado también la presencia/ ausencia de artefactos de morfología autóctona, lo cual claramente no es el caso. Por lo tanto, puede sugerirse que los datos evidencian que la disponibilidad, acceso e incorporación de objetos de cultura material foránea fueron comparativamente mucho más frecuentes en PCM que en TDF.

Para integrar la información sobre materias primas y morfologías a nivel de presencia/ ausencia en sitios a escala regional, se han comparado las Figuras 1 y 2. Así, se nota que: a) el uso de materias primas alóctonas se encuentra ampliamente distribuido en términos espaciales, ya que en todas las regiones se registra predominio de sitios con presencia de materias primas "locales + alóctonas" o paridad de éstos con sitios de materias primas alóctonas y b) contrariamente, las morfologías locales - solas o en paridad con las "locales + alóctonas" - son las de mayor distribución espacial en todas las regiones. Dado que se registran aún más casos de sitios con morfologías locales con respecto a sitios con materias primas locales, ello sugiere que podría haber existido un uso de materias primas alóctonas para manufacturar morfologías locales. En la próxima sección exploramos las tendencias cuantitativas subyacentes a estas distribuciones de artefactos según sus morfologías y materias primas a escala inter-regional. 


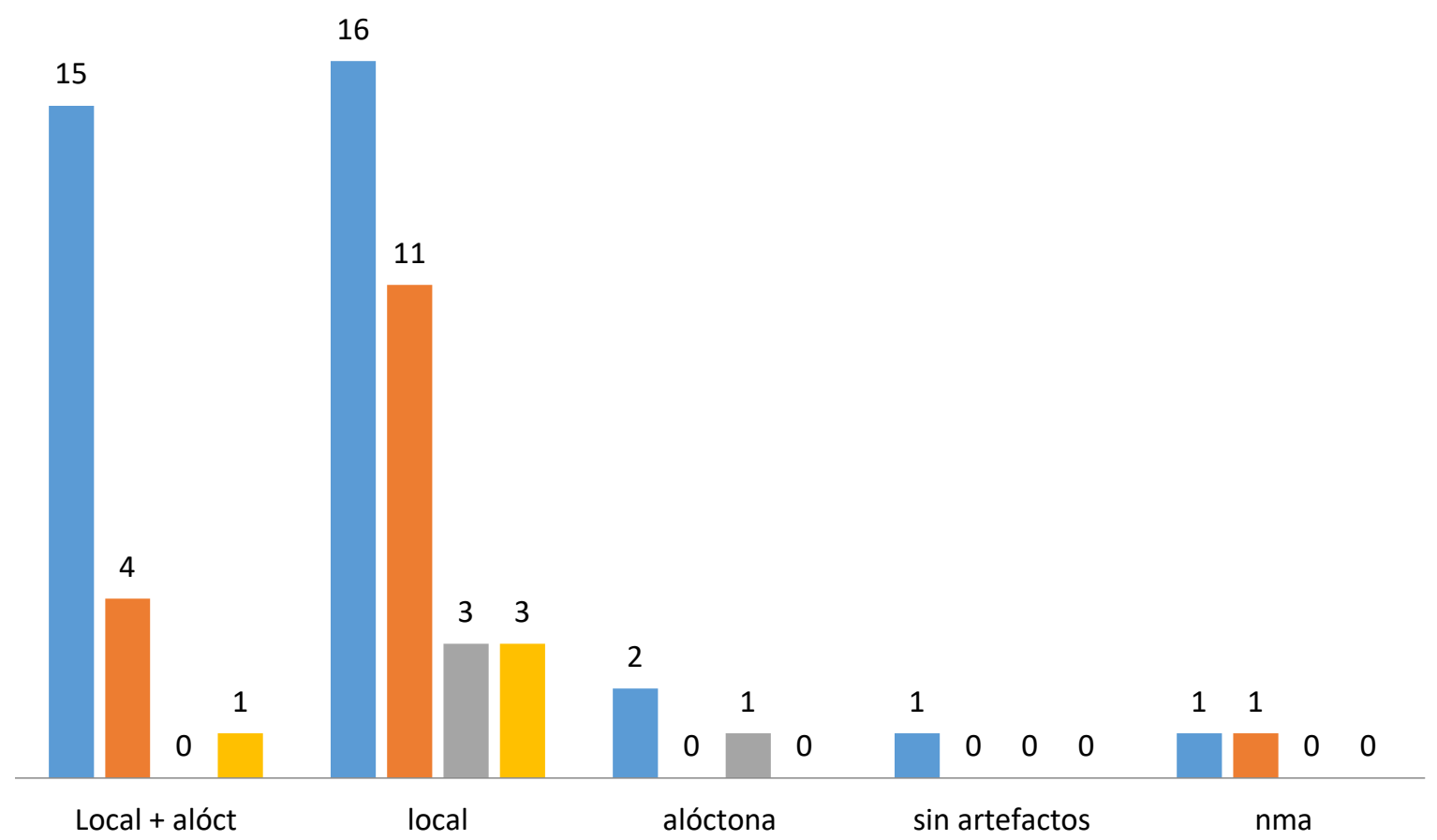

Figura 3. Cantidad de sitios con de artefactos de morfologías locales y/u occidentales, por región.

\begin{tabular}{|c|c|c|c|c|c|c|c|c|}
\hline \multirow{2}{*}{ Morfología } & \multicolumn{2}{|r|}{ PCM } & \multicolumn{2}{|r|}{ TDF C-N } & \multicolumn{2}{|r|}{ TDF SE } & \multicolumn{2}{|r|}{ TED Sur } \\
\hline & NTi & Frec. y/o diag. & NTi & Frec. y/o diag. & NTi & Frec. y/o diag. & $\mathrm{NTi}$ & Frec. y/o diag. \\
\hline $\begin{array}{l}\text { Morfología } \\
\text { local }\end{array}$ & 34 & $\begin{array}{c}\text { lascas, raspadores, } \\
\text { puntas proyectil, } \\
\text { raederas, cerámica, } \\
\text { etc. }\end{array}$ & 23 & $\begin{array}{l}\text { lascas, raederas, } \\
\text { puntas proyectil, } \\
\text { cuentas, } \\
\text { raspadores, etc. }\end{array}$ & 15 & $\begin{array}{c}\text { puntas arpón, } \\
\text { puntas proyectil, } \\
\text { raederas, núcleos, } \\
\text { etc. }\end{array}$ & 20 & $\begin{array}{c}\text { raederas, } \\
\text { raspadores, puntas } \\
\text { proyectil, punzones, } \\
\text { puntas arpón, etc. }\end{array}$ \\
\hline $\begin{array}{l}\text { Morfología } \\
\text { alóctona }\end{array}$ & 35 & $\begin{array}{l}\text { cuentas, cazuelas } \\
\text { botellas, clavos, } \\
\text { tenedor, cuchillo, } \\
\text { zuncho, textil, etc. }\end{array}$ & 6 & $\begin{array}{l}\text { porrones, discos, } \\
\text { clavos, leznas, } \\
\text { botones, formones }\end{array}$ & o & 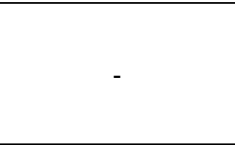 & 1 & botones \\
\hline Total & 69 & - & 29 & - & 15 & - & 21 & - \\
\hline
\end{tabular}

Tabla 4. Morfologías de artefactos registradas en cada región. Referencias: NTi: N Tipos, Frec. y/o diag.: tipos de artefactos más frecuentes y/o diagnósticos

\section{Análisis artefactual, materias primas y morfologías}

En esta sección evaluamos de forma combinada las materias primas y morfologías en las que han sido confeccionados los artefactos, su distribución en los sitios, la cantidad de artefactos y de tipos identificados. Para ello, siguiendo los criterios explicitados en la metodología, clasificamos los artefactos en: a) netamente locales, b) netamente alóctonos y c) mixtos (Tabla 5).

$\mathrm{Al}$ analizar la información a escala de los artefactos se refinan las tendencias para PCM y TDF. En PCM, los artefactos netamente locales se encuentran en el 63\% de los 44 sitios, representando el $61 \%$ de los 12.026 artefactos totales, divididos en 34 tipos de artefactos identificados. Los artefactos netamente alóctonos están en el 34\% de los 44 sitios de PMC, representando el 25\% del total de artefactos y 35 tipos (uno más que 
para los netamente locales). Finalmente, los artefactos mixtos se encuentran presentes en el $43 \%$ de los sitios, con una menor proporción de artefactos (15\% del total) y con muchos menos tipos de artefactos $(n=5$ : raspadores, lascas y fragmentos de filos [todos en vidrio o gres], aros y tupos [de plata, a partir de monedas ${ }^{10}$ ]). Esto implica que en PCM se puede distinguir: a) una alta producción y variabilidad de artefactos netamente locales, consistente con una mayor distribución espacial (intersitios) que los artefactos netamente alóctonos y los mixtos y b) que los netamente alóctonos poseen levemente mayor variedad de tipos artefactuales, pero en menor frecuencia con respecto al total de artefactos y con una distribución espacial más restringida. La cuasiparidad de tipos locales/ alóctonos y la importante proporción de artefactos alóctonos señala que la negociación de categorías culturales se inclinó por la adición al repertorio y no por el reemplazo de categorías artefactuales. Los artefactos mixtos, que evidencian comportamientos de reciclaje e incorporación de nuevas materias primas, muestran más extensión espacial en cantidad de sitios que los netamente alóctonos, aunque muchos menos tipos. Esto último significaría que la identificación de artefactos alóctonos como potenciales fuentes de nuevas materias primas a ser recicladas en tipos previamente conocidos fue un comportamiento restringido a determinados artefactos alóctonos (aquellos en vidrio, loza y algunos de metal). Interesantemente dicho reciclaje operó tanto para producir instrumentos como adornos personales, demostrando que las negociaciones de categorías culturales se orientaron a esferas de la práctica, tanto utilitarias como ornamentales.

En TDF C-N se registran dos tendencias opuestas. Por una parte, los artefactos mixtos, que están presentes en el $50 \%$ de los sitios, son los más frecuentes ya que representan $75,9 \%$ del total de artefactos: ello es debido a que la gran mayoría son lascas de vidrio ( $\mathrm{n}=4.358)$, razón por la cual la variabilidad morfológica se reduce solamente a tres tipos artefactuales (lascas, puntas de proyectil y raspadores). Contrariamente, los artefactos locales, que presentes en el $100 \%$ de los 16 sitios de esta región, son comparativamente menos frecuentes, representando el $24 \%$ del total, pero registran una alta variabilidad morfológica representada en 23 tipos. Finalmente, los artefactos netamente alóctonos están presentes en el 38\% de los sitios pero en muy baja proporción ( $0,1 \%$ del total de 5.931 artefactos) y con muy pocos tipos $(n=6)$. De esta manera, en el caso de TDF C-N se observa una mayor producción de artefactos mixtos — sobrerrepresentados por las lascas - pero con pocos tipos artefactuales. Contrariamente, los artefactos netamente locales evidencian una mayor variabilidad tecnológica pero con una menor producción. Todo esto indicaría una muy frecuente incorporación de las materias primas alóctonas pero para confeccionar muy pocos tipos artefactuales en morfologías tradicionales. Sin embargo, pese a que los artefactos mixtos son los de mayor frecuencia, su presencia en la mitad de los sitios indicaría una distribución espacial importante pero comparativamente acotada respecto de la distribución de los artefactos netamente locales, que son menos frecuentes pero se distribuyen en la totalidad de sitios registrados en la región, corroborando el mantenimiento de una amplia dispersión de las prácticas tecnológicas tradicionales. Asimismo, dada su extrema baja frecuencia, era esperable que la distribución espacial de los artefactos netamente alóctonos fuera acotada. Aun así, es destacable que la proporción artefactos/sitios (Tabla 5) indica que existió una considerable dispersión de estos artefactos en distintos loci de uso/depositación. Ello sugiere una alta circulación en el espacio, posiblemente debido a su valoración como objetos utilitarios y, en algunos casos, potencialmente ornamentales (ver Tabla 4).

Siguiendo esta tendencia, el caso de TDF Sur muestra uno de los comportamientos más conservadores en cuanto a la incorporación de nuevas materias primas y morfologías, aunque el bajo $\mathrm{N}$ de sitios publicados impide generalizar las tendencias. Los artefactos netamente locales, que están distribuidos en el 60\% de los cinco sitios, representan el $98 \%$ del total de 1.166 artefactos y tienen la mayor variabilidad tipológica (20 tipos). Los netamente alóctonos, que fueron hallados todos concentrados en un solo sitio, constituyen el 1\% de los artefactos, de un solo tipo (botones). Los artefactos
10. La fundición de metales especialmente la plata-fue una técnica aprendida por los Aonikenk de los Günnüna kenna y los Mapuches (Aguerre, 2000) y no de los europeos. Los casos arqueológicos se indican como tupos y colgantes confeccionados a partir de monedas de plata y no plata nativa. 


\begin{tabular}{|c|c|c|c|c|c|c|c|c|c|c|c|c|}
\hline \multirow{2}{*}{ Tipos } & \multicolumn{3}{|c|}{ PC-M } & \multicolumn{3}{|c|}{ TDF C-N } & \multicolumn{3}{|c|}{ TDF Sur } & \multicolumn{3}{|c|}{ TDF Sudeste } \\
\hline & Nsi & Nar & Nti & Nsi & Nar & Nti & Nsi & Nar & $\mathrm{Nti}$ & Nsi & Nar & $\mathrm{Nti}$ \\
\hline Netamente locales & 28 & 7.284 & 34 & 16 & 1.408 & 23 & 3 & 1.154 & 20 & 3 & 247 & 15 \\
\hline Netamente alóctonos & 15 & 3.016 & 35 & 6 & 9 & 6 & 1 & 6 & 1 & o & o & o \\
\hline Mixtos & 19 & 1.726 & 5 & 8 & 4.514 & 3 & 4 & 6 & 3 & 2 & 8 & 2 \\
\hline Totales & 44 & 12.026 & $* * *$ & 17 & 5.931 & $* * *$ & 5 & 1.166 & *** & 5 & 255 & $* * *$ \\
\hline
\end{tabular}

Tabla 5. Tipos de artefactos locales alóctonos o mixtos, por región. Referencias: Nsi: $N$ sitios, Nar: $N$ artefactos, Nti: $N$ tipos. Nótese que el Nsi es el $N$ de sitios analizados y no es el producto de la sumatoria de sitios en los que se registraron artefactos locales/alóctonos/mixtos, ya que dos o más categorías de éstos pueden aparecer en un mismo sitio.

11. Investigaciones en curso en este sector generarían nuevos datos que alterarían estas proporciones (F. Zangrando, comunicación personal, febrero 2018). mixtos son también poco frecuentes ( $1 \%$ del total) y abarcan muy pocos tipos $(\mathrm{n}=3$ : raspadores, raederas y lascas) pero interesantemente tienen una mayor distribución espacial ya que fueron hallados en el $80 \%$ de los sitios. De esta manera, se destaca un claro predominio de artefactos netamente locales, una baja incorporación de artefactos netamente alóctonos (pese a que la información de 107 fuentes histórico-etnográficas [Saletta, 2015] indica lo contrario) y un escaso uso del reciclado de materias primas alóctonas para la confección de artefactos en morfologías locales. Cabe notar que TDF Sur tuvo contacto de manera más tardía con europeos, lo cual podría haber reducido inicialmente el manejo de cultura material alóctona por parte de las poblaciones locales. Luego de 1869 los encuentros fueron más intensos (pero restringidos a ciertos puntos en el espacio, Bridges, [1948] 2005), lo cual habría aumentado las posibilidades de interacción. A su vez, las tendencias inferidas pueden ser producto del pequeño tamaño de la muestra por lo cual nuevas investigaciones podrían cambiarlas.

El caso de TDF SE acentúa aún más la tendencia expresada en TDF Sur, ya que pese a haber recibido viajeros desde 1624 en adelante, no fueron hallados artefactos netamente alóctonos en ninguno de los cinco sitios. Los artefactos netamente locales dominan la muestra, ya que están presentes en el $60 \%$ de los cinco sitios y representan el $97 \%$ del total de 255 artefactos, con 20 tipos artefactuales. Los artefactos mixtos están presentes en el $40 \%$ de los sitios pero en muy baja proporción (3\% del total), identificándose dos tipos artefactuales (puntas de proyectil de vidrio y lascas de loza). Así, los nuevos artefactos traídos por europeos o que llegaban a las costas producto de los naufragios fueron percibidos como materia prima para la confección de artefactos de formas tradicionales. Pero, a pesar de tener una mayor frecuencia de contactos directos o indirectos con los europeos (incluyendo 61 naufragios, Saletta, 2015), no existe aún registro arqueológico que respalde que los grupos de TDF SE incorporaran artefactos netamente alóctonos. Como en el caso de TDF Sur, estas tendencias pueden ser producto del número bajo de casos y futuras investigaciones podrían cambiar este panorama $^{11}$.

En síntesis, centrándonos en la incorporación de "nuevos artefactos" (sean netamente alóctonos o mixtos) en estos "nuevos mundos" resulta notorio que, en términos cuantitativos absolutos, si bien en PCM se registra mayor frecuencia y distribución espacial de artefactos locales, esta región lidera la tendencia cuantitativa en la incorporación de artefactos alóctonos en la producción de artefactos mixtos. A diferencia de ello, TDF C-N es la única región que registra una mayor frecuencia de artefactos mixtos, aunque con una distribución espacial intermedia. Contrariamente, TDF Sur y TDF SE registran una baja representación de artefactos alóctonos y mixtos, lo cual indicaría un comportamiento mucho más conservador y reticente a la negociación de nuevas categorías tecnológicas que las sociedades de PCM y TDF C-N. A continuación se analizan y discuten las condiciones bajo las cuales se habrían estructurado estas tendencias. 


\section{Discusión y conclusiones: acerca de condiciones objetivas y categorías tecnológicas en Fuego-Patagonia}

A partir de los datos sobre diversidad artefactual, evaluada a partir de las materias primas y de morfologías artefactuales analizadas para los materiales hallados en los 70 sitios post-contacto, se observa una clara tendencia general al uso de materiales y formas de artefactos de carácter local, en tanto que la incorporación de nuevos recursos tecnológicos operó especialmente como fuente de materia prima para la manufactura de artefactos conservando las morfologías tradicionales. Sin embargo, es posible notar algunas diferencias interregionales que señalarían negociaciones diferenciales sobre estos nuevos recursos y que permiten inferir la aplicación de diferentes marcos lógicos de cada grupo.

En PCM la oferta de nuevos recursos de cultura material operó dentro de marcos lógicos nativos más abiertos (dispuestos a incorporar algunos de estos nuevos recursos) (Sahlins, [1977] 2008) junto a la presencia de tecnologías adaptables a usarlos. Esto dio lugar a una proporción de artefactos netamente alóctonos comparativamente mayor que en el resto de las regiones bajo estudio. Como parte de estos factores identificamos: a) una mayor disponibilidad y abundancia de materias primas alóctonas, debido a un mayor número de contactos y a la temprana fundación de poblados y fuertes en el siglo XVIII (Buscaglia, 2015; Gorla, 1983; Nacuzzi, 2005; Senatore et al., 2007), b) la adopción temprana del caballo como tecnología de transporte que permitió el aumento del volumen y peso transportado y c) la incorporación de nuevos ítems de subsistencia (mate, azúcar, tabaco, alcohol) que promovieron la adopción de nuevos tipos de artefactos (tales como mate, pava, bombilla, pipas, porrones, etc.).

Estas condiciones facilitaron que los grupos de PCM pudieran incorporar el 25\% de artefactos netamente alóctonos aunque su distribución espacial fuera algo acotada (37\% de los sitios). La gran diversidad de tipos artefactuales alóctonos identificados $(\mathrm{N}=35)$ es indicativa tanto de la variabilidad disponible como de la adoptada. Asimismo, entre los artefactos mixtos se destaca el reciclaje de monedas como ornamentos, que implica una valoración del metal como materia prima por sobre su valor monetario. Así, sin negar que en otras situaciones las monedas fueran usadas como valor de cambio, en este caso se las utilizó por su valor de uso, posiblemente por su maleabilidad y por su brillo, para la producción de tupos y aros mediante una tecnología ya conocida -la "platería mapuche"-. En conjunto, estos indicadores muestran grupos cuyos marcos lógicos percibieron y negociaron positivamente la adición de nuevos artefactos con nuevas materias primas y morfologías que, probablemente, estaban relacionados con la adquisición de nuevos gustos y/o nuevas tecnologías (el mate como bebida o el caballo como tecnología de transporte).

En TDF, la adopción de artefactos netamente alóctonos parece no haber contado con las mismas condiciones objetivas que PCM. La menor frecuencia de contactos y el establecimiento más tardío de poblaciones europeo-criollas (siglo XIX) generaron comparativamente un menor flujo de nuevos artefactos alóctonos a estas regiones. De ahí que los porcentajes de artefactos netamente alóctonos bajen a 0,1\% en TDF C-N (con solo nueve tipos de artefactos identificados), al tiempo que en TDF Sur los artefactos alóctonos representan el 1\% (con un solo tipo identificado: botones) y se encuentran ausentes en TDF SE. Llamativamente, la región de TDF Sur contaba con el uso de canoas como tecnología de transporte (Orquera y Piana, [1999] 2015), razón por la cual no se puede asignar la falta de incorporación de estos artefactos exclusivamente a cuestiones relativas a la falta de capacidad para su transporte.

Sin embargo, pese a condiciones objetivas que limitaron la disponibilidad y abundancia relativa de recursos tecnológicos, los artefactos mixtos están presentes en porcentajes similares en tres de las cuatro regiones bajo análisis. Estos artefactos 
12. No se descarta que esta baja variabilidad en los tipos de artefactos sea producto de procesos de preservación diferenciales sobre otras materias primas empleadas para la confección de artefactos mixtos ( $p$. ej. cuchillos manufacturados con flejes de sunchos, Bridges, [1948] 2005). son simultáneamente indicativos de comportamientos de reciclaje y de negociación de categorías tecnológicas asociadas a la materia prima. Así en PCM, los artefactos mixtos representan el 15\% del total, pero tienen una mayor distribución espacial en los sitios que los netamente alóctonos (43\% contra 34\%). Sin embargo, el uso de materias primas alóctonas se limitó a la confección de seis tipos artefactuales (especialmente raspadores, filos largos, etc.). Esta orientación en la selección se relacionaría con que estas nuevas materias primas (sobre todo vidrio y, en menor medida, loza) podrían ser usadas para tipos artefactuales altamente utilizados en la tecnología cazadorarecolectora tradicional. En TDF, los artefactos mixtos son más abundantes que en PCM, tanto en distribución espacial como en proporción de piezas. En TDF C-N los artefactos mixtos representan el 79,9\% del total y están presentes en más de la mitad de los 17 sitios (59\%), ello revela un alto nivel de reutilización de artefactos alóctonos (enteros o fragmentos) como materias primas para la producción de artefactos de morfologías locales, sugiriendo una alta injerencia de la agencia indígena local en las negociaciones de categorías tecnológicas y en las prácticas concretas de producción/uso de artefactos. Sin embargo, la variabilidad de estos artefactos mixtos es aún más baja que en PCM con sólo tres tipos identificados (lascas, puntas de proyectil y raspadores) en vidrio. Entonces, algunas categorías tecnológicas asociadas a las materias primas fueron frecuentemente negociadas, pero para pocos tipos de artefactos. Esto puede relacionarse con el hecho de que el vidrio es un muy buen sucedáneo de materias primas líticas de alta calidad para la talla, razón por la cual la decisión y práctica de incorporarlo habría sido estimulada por el alto beneficio técnico y funcional que dicho material podía aportar a estas sociedades. A su vez, la familiaridad que sus cualidades físico-mecánicas ofrecen respecto de las materias primas líticas habría facilitado enormemente su adopción, ya que la utilización del vidrio habría permitido mantener el uso de técnicas de talla y retoque previamente conocidas. En tal sentido, podría decirse que esta habría sido una negociación de bajo costo comparativo en términos de procedimientos tecnológicos e inversión laboral y de alto beneficio en términos de performance de la materia prima en cuestión. Existe también la posibilidad de que esta adopción tecnológica del vidrio hubiera tenido además implicaciones de índole ideológica y/o simbólica en términos de las relaciones sociales de producción involucradas (Silliman, 2010), pero no hemos hallado aún información que nos permita verificar esta hipótesis ${ }^{12}$..

Otra situación se registra en TDF Sur, donde los artefactos mixtos representan el 1\% del total pero están distribuidos en el $80 \%$ de los sitios en tres tipos artefactuales (raspadores, raederas y lascas) todos ellos de vidrio. Aquí hay baja proporción de estos artefactos pero con gran dispersión espacial, aunque el $\mathrm{N}$ total de sitios es bajo (debe tenerse en cuenta como sesgo dentro de estas proporciones), lo que sugeriría un cierto nivel de circulación territorial de estos materiales. El comportamiento de reciclaje de artefactos alóctonos y su transformación en artefactos de formas tradicionales también se registró en las fuentes. Por ejemplo, Weddell (1825, p. 149) relató que una copa de vidrio regalada a unos canoeros fue rota y repartida entre varias personas, que utilizaron los fragmentos como piezas de un collar. Aquí el valor de uso original (occidental y utilitario) de la pieza fue transformado para adecuarlo a otro valor de uso (indígena y ornamental). Entonces, tanto en los casos arqueológicos como escritos, en TDF Sur los artefactos de morfologías percibidas como de poca utilidad, fueron transformados por estos cazadores-recolectores de alta movilidad en elementos de morfologías tradicionales. Ello señala la percepción y negociación de objetos de cultura material foráneos según categorías tecnológicas propias, que los clasifican e incorporan como fuentes de materia prima, reciclándolos tanto para funciones utilitarias como ornamentales.

En TDF SE, los artefactos mixtos representan sólo 3\% del total, con una baja variabilidad de tipos $(\mathrm{N}=3)$ ( $40 \%$ de los sitios). Nuevamente, como en las demás regiones, se negociaron las categorías culturales asociadas a la materia prima (vidrio), 
adicionándolas al repertorio para confeccionar artefactos en morfologías conocidas (puntas de proyectil, raspadores), lo que también está registrado en las fuentes (Cook, 1821).

En las cuatro regiones, el vidrio y la loza fueron incorporados como sucedáneos de los recursos líticos (Nuevo Delaunay et al., 2017; Saletta, 2015; Saletta y Fiore, 2018a; Saletta y Sacchi, 2019). El vidrio no reemplazó a ningún material sino que se adicionó como un tipo más de materia prima para la producción de morfologías tradicionales (Saletta y Fiore, 2018a; Saletta y Sacchi, 2019). Dado que en TDF las materias primas de buena calidad tienen una menor disponibilidad y/o abundancia relativa (Borrazzo, 2010), esta podría ser una de las razones por las que el vidrio fue seleccionado positivamente como materia prima. Del total de 38 puntas de proyectil halladas en sitios de TDF C-N y SE, el vidrio fue usado para producir 18, distribuidas en cinco sitios de TDF C-N y dos de TDF SE. Asimismo, los raspadores de vidrio suman sólo ocho, mientras que los líticos llegan a 85. Contrariamente, en TDF Sur el vidrio no fue usado para confeccionar puntas de proyectil ( $\mathrm{n}=75$, todas líticas), pero sí para raspadores $(\mathrm{n}=3$ de un total de 102). Estos datos podrían ser indicadores de negociaciones diferenciales del reciclaje de artefactos/fragmentos de vidrio como materia prima para la confección de estos instrumentos, ya que en todas las regiones se registra uso del vidrio pero los tipos de artefactos a ser producidos sobre esta materia prima muestran frecuencias distintas en cada región.

En PCM, donde la disponibilidad de materias primas líticas es mayor, la tendencia es la inversa: las puntas de proyectil son líticas $(\mathrm{n}=48)$ y no hay puntas de proyectil de vidrio, mientras que los raspadores líticos son 105 y los de vidrio son 786. Estas diferencias regionales en las proporciones de usos de materias primas líticas y vidrio podrían ser resultado de diferencias en las negociaciones de categorías y prácticas tecnológicas. Por ejemplo, estas negociaciones diferenciales podrían ser resultado de los diferentes géneros involucrados en la producción y uso de estos artefactos (Saletta, 2015). La información obtenida del relevamiento de 208 fuentes escritas por 100 autores sobre las cuatro regiones (Saletta, 2015) indica que quienes usaban y manufacturaban las puntas de proyectil eran varones, en tanto que los raspadores eran confeccionados y usados por mujeres. Otra variable a tomar en cuenta a futuro es la funcionalidad de los artefactos en cuestión, ya que las tareas para la cuales se usaban los raspadores, por ejemplo, podrían haber influido sobre las elecciones de las materias primas.

El análisis de los 19.455 artefactos en los 70 sitios indígenas temporalmente asignados entre los siglos XVI y XX muestra que en todas estas regiones se utilizaron nuevos artefactos (especialmente vidrio) como fuentes de materias primas para confeccionar unas pocas morfologías tradicionales. Ello indicaría que en todas las regiones primó la negociación de categorías tecnológicas asociadas a la materia prima, un aspecto de la tecnología que es frecuentemente contrastado puesto que parece más lábil a sustituciones siempre y cuando no se pongan en riesgo la funcionalidad y performance del artefacto. Contrariamente, los cambios en las morfologías - especialmente de las partes activas - de los artefactos afectan directamente a la funcionalidad y performance de la pieza, por lo cual son menos negociables (Álvarez, 2003; Nelson, 1991). Las morfologías de los artefactos en materias primas alóctonas no difieren en lo sustancial de las de sus sucedáneos líticos (Saletta y Fiore, 2018a; Saletta y Sacchi, en prensa) por lo que es posible afirmar que estas formas fueron intencionalmente conservadas. Para finalizar, cabe mencionar que este tipo de trabajos que analizan y comparan gran cantidad de sitios a escala interregional son útiles para establecer tendencias sobre procesos de corta duración - en términos arqueológicos-cuya visibilidad arqueológica a escala de sitio puede ser mucho menor o incluso nula. Las tendencias regionales establecidas en el uso de artefactos, divididos en categorías de análisis simples, evitando la subdivisión taxonómica que puede oscurecer cuestiones relativas 
a las prácticas generales del uso de artefactos (Silliman, 2010), permiten visualizar las decisiones que tomaron los grupos de cada región sobre qué seleccionaron y cómo usaron estos nuevos recursos tecnológicos. Los grupos seleccionaron activamente los nuevos materiales de acuerdo a sus marcos lógicos de interpretación, incluyendo qué categorías tecnológicas eran referenciadas y qué habilidades técnicas requerían estas en la práctica. Si bien se ha identificado la incorporación de artefactos netamente alóctonos, el resultado más llamativo de esta investigación es la producción de artefactos mixtos, mediante el reciclaje de objetos alóctonos como materias primas. En cambio, las formas tradicionales se mantuvieron, mostrando aspectos de la tecnología más resilientes (sensu Fiore, 2014) a la puesta en referencia y posterior transformación. Esta última tendencia, la resiliencia de las formas tradicionales, aún en materias primas del tipo industrial, así como la adición de éstas últimas sin dejar de usar las locales, podrían ser interpretados como indicadores de la agencia activa de las sociedades indígenas en la interpretación de los nuevos acontecimientos históricos a medida que éstos se desarrollaban (Sahlins, [1977] 2008). La persistencia de las morfologías tradicionales, así como la continuidad en el uso de materias primas locales, implicarían la acción de una estrategia destinada a continuar, mantener y transmitir los conocimientos sobre manufactura de artefactos entre generaciones (Álvarez, 2003). Esta acción revelaría que no todos los mecanismos empleados por las sociedades indígenas frente a la invasión de su territorio pueden ser encuadrados como una resistencia pasiva, sino que muchas de ellas habrían sido resultado de estrategias activas de mantenimiento de tradiciones culturales (Funari y Senatore, 2015; Sahlins, [1977] 2008; Silliman, 2010).

Comparativamente, se registra una mayor abundancia y disponibilidad de recursos tecnológicos alóctonos en PCM, que se refleja en la diversidad de tipos artefactuales adicionados, simultánea al mantenimiento de categorías tecnológicas nativas, indicando una plasticidad al aumento del repertorio artefactual. Contrariamente, el rango de repertorio artefactual en las tres regiones de TDF no se vio tan ampliado, resultando en toolkits comparativamente más conservadores. Ello permite arrojar luz sobre la existencia de distintos procesos locales de contacto e interacción dentro de contextos coloniales, contribuyendo así a la discusión de que el colonialismo no fue un proceso homogéneo ni unidireccional (Funari y Senatore, 2015; Silliman, 2010). Su estudio requiere tanto de la combinación de múltiples escalas espaciales (en nuestros casos de estudio, escalas de sitio, región e interregional), como de la búsqueda de procesos sutiles de construcciones de situaciones de contacto, en los cuales la agencia indígena emerge de manera más evidente cuando los artefactos se pesquisan mediante criterios que eviten una taxonomía tipológica homogeneizadora (Silliman, 2010): la categoría de "artefactos mixtos" muestra aquí su relevancia analítica para evidenciar estas agencias.

En esta aproximación a escala interregional se ha generado un panorama preliminar sobre la frecuencia, variabilidad y distribución espacial de tipos de artefactos locales, alóctonos y mixtos en Fuego-Patagonia durante los momentos de contacto indígenasoccidentales. Futuras evaluaciones sobre variables relativas a funcionalidad de artefactos, tipos de contextos de uso/descarte de los artefactos, movilidad, distribución biogeográfica de los sitios y género de productores/usuarios, permitirán refinar estas primeras tendencias sobre los nuevos artefactos en el "nuevo mundo".

\section{Agradecimientos}

Este trabajo es parte de los resultados de investigaciones doctoral y postdoctoral de M. J. Saletta financiadas por becas de CONICET. Agradecemos a Luis Orquera por la lectura de los manuscritos y a Francisco Zangrando por sus comentarios sobre las actuales investigaciones en península Mitre. A Ana Butto y Mariela Videla por la confección de la Figura 1. A los evaluadores/as por sus interesantes y constructivas sugerencias. 


\section{Referencias citadas}

"Aguerre, A. M. (2000). Las vidas de Pati en la toldería Tehuelche del Río Pinturas y el después. Buenos Aires: Facultad de Filosofía y Letras, UBA.

»Álvarez, M. (2003). Organización tecnológica en el Canal Beagle. El caso de Túnel I (Tierra del Fuego, Argentina). (Tesis doctoral inédita), Universidad de Buenos Aires, Buenos Aires.

" Aragone, A. (2009). Los conjuntos arqueofaunísticos de los sitios Médanos Lago Posadas (cuenca baja) y parapetos Cerro Pampa (meseta alta). Provincia de Santa Cruz. En M. Salemme, F. Santiago, M. Álvarez, E. L. Piana y M. E. Mansur (Eds.), Arqueología de la Patagonia. Una mirada desde el último confín (Tomo II pp. 679-689). Ushuaia: Utopías.

» Aragone, A. y Cassiodoro, G. (2009). Registro faunístico de los parapetos de Cerro Pampa 2. Noroeste de la provincia de Santa Cruz. En A. Austral y M. Tamagnini (Eds.), Problemáticas de Arqueología Contemporánea. (Tomo III pp. 1027-1929). Río Cuarto: Universidad Nacional de Río Cuarto. Facultad de Ciencias Humanas.

》Aschero, C., Belleli, C. y Goñi, R. (1992-1993). Avances en las investigaciones arqueológicas en el Parque Nacional Perito Moreno (provincia de Santa Cruz, Patagonia Argentina). Cuadernos del Instituto Nacional de Antropología y Pensamiento Latinoamericano, 14, 143170.

》Bandieri, S. (2005). Historia de la Patagonia ( $1^{\circ}$ Ed.). Buenos Aires: Sudamericana.

" Belardi, J. B., Carballo Marina, F., Nuevo Delaunay, A. y De Angelis, H. (2013). Raspadores de vidrio y de gres cerámico en la reserva tehuelche (Aonikenk) de Camusu Aike: aportes al conocimiento de poblaciones indígenas de los siglos XIX y XX en el territorio de Santa Cruz. Relaciones de la Sociedad Argentina de Antropología, XXXVIII(1), 37-57.

» Belza, J. E. (1974). En la Isla del Fuego. Encuentros. Buenos Aires: Publicación del Instituto de Investigaciones Históricas Tierra del Fuego.

»Borrazzo, K. (2010). Arqueología de los esteparios fueguinos. (Tesis doctoral inédita). Facultad de Filosofía y Letras, Universidad de Buenos Aires, Argentina.

"Borrero, L. A. (1979). Excavaciones arqueológicas en el Alero Cabeza de León, Isla Grande de Tierra del Fuego. Relaciones de la Sociedad Argentina de Antropología, XIII, 255-271.

"Borrero, L. A. (1985). La economía prehistórica de los habitantes del norte de la Isla Grande de Tierra del Fuego. (Tesis doctoral inédita), Universidad de Buenos Aires, Buenos Aires.

» Borrero, L. A. (2001). Los Selk'nam (Ona). Buenos Aires: Galerna Búsqueda de Ayllu.

» Borrero, L. A., Borrazzo, K., Garibotti, I. y Pallo, M. C. (2011). Concentraciones de pilas de rocas en la cuenca superior del río Santa Cruz (Argentina). Magallania, 39(2), 193-206.

» Borrero, L. A. y Franco, N. V. (2005). Arqueología de Cabo Vírgenes, Provincia de Santa Cruz. Actas del XIII Congreso Nacional de Arqueología Argentina (Tomo IV, pp. 29-36). Córdoba: Brujas.

"Borrero, L. A. y Lanata, J. L. (1988). Estrategias adaptativas representadas en los sitios de Estancia María Luisa y Cabo San Pablo. Actas del X Congreso Nacional de Arqueología Argentina (pp. 166-176). Buenos Aires.

» Boschín, M. T. y Nacuzzi, L. R. (1979). Ensayo metodológico para la reconstrucción etnohistórica. Su aplicación a la comprensión del modelo tehuelche meridional. Colegio de Graduados en Antropología. Serie Monográfica, 4, 40-48. 
»Bridges, E. L. ([1948] 2005). El último confín de la Tierra (3 $3^{\underline{a}}$ Ed.). Buenos Aires: Sudamericana-Rumbo Sur.

» Buscaglia, S. (2009). Relaciones de poder y dinámica interétnica en Floridablanca. Una perspectiva histórica y arqueológica (San Julián. Siglo XVIII). (Tesis Doctoral inédita), Facultad de Filosofía y Letras, Universidad de Buenos Aires, Argentina.

» Buscaglia, S. (2015). Indígenas, borbones y enclaves coloniales. Las relaciones interétnicas en el Fuerte San José durante su primera década de funcionamiento (Chubut, 1779-1789). [Corpus en línea]. Archivos virtuales de la alteridad americana, 5(1), http://corpusarchivos. revues.org/1383 (Acceso julio de 2015).

" Buscaglia, S. y Nuviala, V. (2007). Pocos espejitos de colores. La materialidad de las relaciones interétnicas en Floridablanca. En F. Morello, A. Prieto y G. Bahamonde (Eds.), Arqueología de Fuego Patagonia. Levantando piedras, desenterrando huesos... Y develando arcanos (pp. 813-824). Punta Arenas: CEQUA.

"Carballo Marina, F., Belardi, J. B., Espinosa, S. y Ercolano, B. (2000-2002). Tecnología y movilidad en la cuenca media del río Coyle, Santa Cruz. Cuadernos del Instituto Nacional de Antropología y Pensamiento Latinoamericano, 19, 89-107.

"Carballo Marina, F., Belardi, J. B. y Sáenz, J. L. (2011). Distribución del registro arqueológico en la unidad de paisajes terrazas, cuenca media del río Coyle, Santa Cruz, Argentina. Magallania, 39(2), 207-222.

"Cassiodoro, G., Aragone, A. y Re, A. (2004). Más allá de los Chenques. Registro arqueológico a cielo abierto en la cuenca de los lagos Salitroso y Posadas Pueyrredón. En M. T. Civalero, P. Fernández y G. Guráieb (Eds.), Contra Viento y Marea. Arqueología de Patagonia (pp. 325-338). Buenos Aires: Instituto Nacional de Antropología y Pensamiento Latinoamericano.

"Cassiodoro, G. y García Guráieb, S. (2009). Análisis del registro tecnológico y osteológico de los entierros humanos en el Holoceno tardío en el Lago Salitroso (Santa Cruz): un aporte al estudio del comportamiento mortuorio de cazadores-recolectores. En M. Salemme, F. Santiago, M. Álvarez, E. L. Piana y M. E. Mansur (Eds.), Arqueología de la Patagonia. Una mirada desde el último confín (Tomo II, pp. 613-628). Ushuaia: Utopías.

»Chapman, A. (1986). Los Selk'nam (la vida de los Onas). Buenos Aires: Emecé.

"Charlin, J. (2012). Materias primas líticas y uso del espacio en las nacientes del río Gallegos: el caso de Laguna Cóndor (Estancia Glencross, Santa Cruz, Argentina). Magallania, 40(I), 163-184.

» Cirigliano, N. (2013). Primeras aproximaciones al sitio Cañadón León 1. Los materiales de superficie (provincia de Santa Cruz, Argentina). En A. F. Zangrando, R. Barberena; A. Gil, G. Neme, M. Giardina, L. Luna, C. Otaola, L. Salgán, A. Tívoli (Ed.), Tendencias teórico-metodológicas y casos de estudio de la arqueología de la Patagonia (pp. 317-324). San Rafael: Sociedad Argentina de Antropología, Instituto Nacional de Antropología Pensamiento Latinoamericano, Museo de Historia Natural.

" Cirigliano, N. y Vommaro, M. (2014). Un asentamiento histórico en cercanías del cañadón Mercerá (provincia de Santa Cruz, Argentina). En M. L. Castro Esnal, M. Funes, M. Grosso, N. Kuperszmit, A. Murgo y G. Romero (Eds.), Entre pasados y presentes IV: estudios contemporáneos en ciencias antropológicas (pp. 280-296). Buenos Aires: Asociación Amigos del Instituto Nacional de Antropología.

" Cook, J. (1821). The three voyages of Captain James Cook round the world. Complete in seven volumes. Londres: Longman, Hurst, Rees, Orme, and Brown.

»Fiore, D. (2002). Body Painting in Tierra del Fuego. The power of images in the uttermost part of the world (Tesis Doctoral inédita), University of London, Londres. 
»Fiore, D. (2004). Pieles rojas en el confín del mundo. La valoración de las pinturas corporales en los registros histórico-etnográficos sobre aborígenes de Tierra del Fuego. Magallania, 32, 29-52.

»Fiore, D. (2007). Arqueología con fotografías: el registro fotográfico en la investigación arqueológica y el caso de Tierra del Fuego. En F. Morello, M. Martinic, A. Prieto y G. Bahamonde (Eds.), Arqueología de Fuego-Patagonia. Levantando piedras, desenterrando huesos... y develando arcanos (pp. 767-778). Punta Arenas: CEQUA.

»Fiore, D. (2014). Pinturas corporales fueguinas. Una arqueología visual. En J. Oria y A. Tívoli (Eds.), Cazadores de mar y tierra. Estudios recientes en arqueología fueguina (pp. 409-433). Ushuaia: Editorial Cultural Tierra del Fuego.

» Franco, N. V., Borrero, L. A., Belardi, J. B., Martín, F., Campan, P., Favier Dubois, C., Stadler, N., Hernández Llosas, M. I., Muñoz, S., Borella, F., Muñoz, F. y Cruz, I. (1999). Arqueología del cordón Baguales y el sistema lacustre al sur del Lago Argentino. Prcehistoria, 3, 65-86.

" Funari, P. y Senatore, X. (Eds.). (2015). Archaeology of Culture, Contact and Colonialism in Spanish and Portuguese America. Heidelberg: Springer.

» Gómez Otero, J. (1989-1990). Cazadores tardíos en la zona fronteriza. Anales del Instituto de Patagonia, 19, 47-71.

»Goñi, R. (2000). Arqueología de momentos históricos fuera de los centros de conquista y colonización: un análisis de caso en el sur de la Patagonia. En J. B. Belardi, F. Carballo Marina y S. Espinosa (Eds.), Desde el País de los Gigantes. Actas de las IV Jornadas de Arqueología de la Patagonia (pp. 283-296). Rio Gallegos: Universidad Nacional de la Patagonia Austral.

» Goñi, R., Barrientos, G. y Cassiodoro, G. (2000-2002). Condiciones previas a la extinción de las poblaciones humanas del sur de Patagonia: una discusión a partir del análisis del registro arqueológico de la cuenca del Lago Salitroso. Cuadernos del Instituto Nacional de Antropología y Pensamiento Latinoamericano, 19, 249-266.

» Goñi, R. y Guráieb, G. (1996). Eran tres aleros... Análisis intersitio de conjuntos artefactuales líticos en el parque Nacional Perito Moreno (Prov. De Santa Cruz). En J. Gómez Otero (Ed.), Arqueología Solo Patagonia (pp. 69-76). Puerto Madryn: Centro Nacional Patagónico.

»Gorla, C. M. (1983). Origen y desarrollo de la ganadería patagónica: 1779-1810. Buenos Aires: Fundación para la Educación, la Ciencia y la Cultura.

» Gusinde, M. ([1931] 1982). Los indios de Tierra del Fuego. Los selk'nam. Buenos Aires: Centro Argentino de Etnología Americana.

» Horwitz, V. (1995). Ocupaciones prehistóricas en el sur de la bahía de San Sebastián (Tierra del Fuego, Argentina). Arqueología, 5, 105-136.

» Horwitz, V., Borrero, L. A. y Casiraghi, M. (1993-1994). San Julio 2 (Tierra del Fuego), Estudios del registro arqueológico. Relaciones de la Sociedad Argentina de Antropología, XIX, 391-415.

» Jackson, D. (1991). Los instrumentos de vidrio de Cuarto Chorrillo, costa de Bahía Santiago, estrecho de Magallanes. Anales del Instituto de la Patagonia, 20, 69-74.

» Mansur, M. E. y Piqué Huerta, R. (Eds.). (2012). Arqueología del Hain. Investigaciones etnoarqueológicas en un sitio ceremonial de la sociedad selknam de Tierra del Fuego. Implicancias teóricas y metodológicas para los estudios arqueológicos. Madrid: Consejo Superior de Investigaciones Científicas. 
» Manzi, L. (1996). Las fuentes etnohistóricas en el análisis de la explotación y manejo de materias primas en grupos cazadores-recolectores pedestres de la Isla Grande de Tierra del Fuego. En J. Gómez Otero (Ed.), Arqueología. Solo Patagonia (pp. 379-88). Puerto Madryn: Centro Nacional Patagónico-Consejo Nacional de Investigaciones Científicas y Técnicas.

» Martinic, M. (1973). Panorama de la colonización en Tierra del Fuego entre 1881 y 1900. Anales del Instituto de Patagonia, IV(1-3), 5-69.

» Martinic, M. (1995). Los Aonikenk. Historia y cultura (1ํed.). Punta Arenas: Ediciones de la Universidad de Magallanes.

» Martinic, M. y Prieto, A. (1976). Hallazgo y excavación de tumba aonikenk en Magallanes. Anales del Instituto de la Patagonia, 7, 95-104.

» Martinic, M. y Prieto, A. (1985-86). Dinamarquero, Encrucijada de rutas indígenas. Anales del Instituto de la Patagonia, 16, 53-83.

» Martinic, M., Prieto, A. y Cárdenas, P. (1995). Hallazgo del asentamiento del jefe aonikenk Mulato en el Valle del Zurdo. Una Prueba de la sedentarización indígena en el período histórico final. Anales del Instituto de la Patagonia, 23, 87-94.

» Martinic, M. y Quiroz, D. (1989-1990). El uso ecuestre entre los Aonikenk. Anales del Instituto de la Patagonia, 19, 29-42.

» Martinic, M. y Roehrs, H. (1991). Hallazgo de un asentamiento colonizador en la costa de Bahía Santiago (estrecho de Magallanes). Evidencias de relación pionero-indígena. Anales del Instituto de la Patagonia, 20, 45-56.

» Massone, M. (1979). Panorama Etnohistórico y Arqueológico de la ocupación Tehuelche y prototehuelche en la costa del Estrecho de Magallanes. Anales del Instituto de la Patagonia, 10, 63-107.

» Massone, M. (1984). Paraderos tehuelches y prototehuelches. Anales del Instituto de la Patagonia, 15, 27-46.

» Massone, M. (1989-1990). Investigaciones arqueológicas en la laguna Thomas Gould (1980-1982). En homenaje al Dr. Junius Bird. Anales del Instituto de la Patagonia, 19, 87-99.

» Massone, M. (2009). Territorialidad, asentamiento, movilidad y construcción de paisajes en el mundo Selk’nam. En M. Salemme, F. Santiago, M. Álvarez, M. Vázquez y M. E. Mansur (Eds.), Arqueología de la Patagonia. Una mirada desde el último confín (Tomo I, pp. 249-263). Ushuaia: Utopías.

» Massone, M. (2010). Los cazadores del viento. Santiago de Chile: Turismochile.

» Massone, M. e Hidalgo, E. (1981). Investigaciones en el Alero Pali Aike. Anales del Instituto de la Patagonia, 12, 125-140.

» Massone, M., Jackson, D. y Prieto, A. (1993). Perspectiva arqueológica de los Selḱnam. Santiago de Chile: Colección de Antropología, Centro de Investigaciones Diego Barros Arana.

» Massone, M., Morrillo, F., Prieto, A., San Roman, M., Martín, F. y Cárdenas, P. (2003). Sitios arqueológicos, restos de cetáceos y territorios locales selk’nam en Bahía Inútil, Tierra del Fuego. Magallania, 31, 45-59.

» Moreno, E. y Videla, B. (2011). Rastreando ausencias: la hipótesis del abandono del uso de los recursos marinos en el momento ecuestre en la Patagonia occidental. Magallania, 36(2), 91-104.

» Muñoz, S. (2004). La explotación de pinnípedos en el sitio arqueológico Punta María 2, Isla Grande de Tierra del Fuego. En M. T. Civalero, P. Fernández y G. Guráieb (Eds.), Contra viento y marea. Arqueología de la Patagonia (pp. 489-496). Buenos Aires: Instituto Nacional de Antropología y Pensamiento Latinoamericano. 
» Muñoz, S. y Belardi, J. B. (2011). Nueva información sobre viejos datos: arqueología del norte de Península Mitre. En A. F. Zangrando, M. Vázquez y A. Tessone (Eds.), Los cazadores recolectores del extremo oriental fueguino. Arqueología de Península Mitre e Isla de los Estados (pp. 171-202). Buenos Aires: Publicaciones de la Sociedad Argentina de Antropología.

» Nacuzzi, L. R. (2005). Identidades impuestas. Buenos Aires: Sociedad Argentina de Antropología.

» Nami, H. y Frink, D. (1999). Cronología obtenida por la tasa del carbono orgánico oxidable (OCR) en Markatch Aike 1 (cuenca del río Chico, Santa Cruz). Anales del Instituto de la Patagonia, 27, 231-237.

» Nelson, M. (1991). The Study of technological organization. Archaeological Method and Theory, 3, 57-100.

» Nuevo Delaunay, A. (2007). Tecnología vítrea en el siglo XX, Lago Strobel (Santa Cruz, Argentina). En F. Morello, M. Martinic, A. Prieto y G. Bahamonde (Eds.), Arqueología de Fuego Patagonia. Levantando piedras, desenterrando huesos... Y develando arcanos (pp. 853-859). Punta Arenas: CEQUA.

» Nuevo Delaunay, A., Belardi, J. B., Carballo Marina, F., Saletta, M. J. y De Angelis, H. (2017). Glass and stoneware knapped tool among hunter-gatherers in southern Patagonia and Tierra del Fuego. Antiquity, 91(359), 1330-1343.

»Orquera, L. A. yPiana, E. L. (1993-1994). Lancha Packewaia: actualización y rectificaciones. Relaciones de la Sociedad Argentina de Antropología, XIX, 325-365.

» Orquera, L. A. y Piana, E. L. (1995). Túnel VII: La excavación. En J. Estévez Escalera y A. Vila Mitjá (Eds.), Encuentros en los conchales fueguinos (pp. 47-81). Barcelona: CSIC.

»Orquera, L. A. y Piana, E. L. (1999). Arqueología de la región del canal de Beagle (Tierra del Fuego, República Argentina). Buenos Aires: Publicaciones de la Sociedad Argentina de Antropología.

»Orquera, L. A. y Piana, E. L. ([1999] 2015). La vida material y social de los Yámana. Buenos Aires: Ediciones Monte Oliva.

»Palermo, M. A. (1986). Reflexiones sobre el Ilamado “complejo ecuestre” en la Argentina. RUNA, XVI, 157-174.

»Piana, E. L. y Orquera, L. A. (1995). Túnel VII: La cronología. En J. Estévez Escalera y A. Vila Mitjá (Eds.), Encuentro en los conchales fueguinos (pp. 105-111). Barcelona: CSIC.

»Piana, E. L., Estévez Escalera, J. y Vila Mitjá, A. (2000). Lanashuaia: un sitio de canoeros del siglo pasado en la costa norte del canal de Beagle. Desde el País de los Gigantes. Perspectivas arqueológicas en Patagonia (Tomo II, pp. 455-469). Rio Gallegos: Universidad Nacional de la Patagonia Austral.

»Piana, E. L., Tessone, A. y Zangrando, A. F. (2006). Contextos mortuorios en la región del canal de Beagle... Del hallazgo fortuito a la búsqueda sistemática. Magallania, 34(1), 103-117.

»Prieto, A. y Schidlowsky, V. (1992). Un enterratorio de niña aonikenk en Laguna Sota. Anales del Instituto de la Patagonia, 21, 63-71.

»Rodríguez-Alegría, E., Scaramelli, F. y Navas Méndez, A. M. (2015). Technological Transformations: Adaptationist, Relativist, and Economic Models in Mexico and Venezuela. En P. Funari y X. Senatore (Eds.), Archaeology of Culture, Contact and Colonialism in Spanish and Portuguese America (pp. 53-78). Heidelberg: Springer.

»Sacchi, M. (2013). A un paso de la laguna. Análisis lítico del sitio Bajo de la Laguna 2, provincia de Santa Cruz. Comechingonia Virtual, 2(2), 216-233. 
»Sahlins, M. ([1977] 2008). Islas de historia. Barcelona: Gedisa.

»Salemme, M., Santiago, F., Suby, J. y Guichón, R. (2007). Arqueología funeraria en el norte de tierra del fuego. Actas del XVI Congreso Nacional de Arqueología Argentina. Tras las Huellas de la Materialidad, pp. 71-77. San Salvador de Jujuy: Universidad Nacional de Jujuy.

»Saletta, M. J. (2010). La incorporación de artefactos y materias primas foráneas en dos sociedades fueguinas. Una evaluación preliminar. En R. Bárcena y H. Chiavazza (Eds.), La Arqueología Argentina en el bicentenario de la Revolución de Mayo. XVII Congreso Nacional de Arqueología Argentina (pp. 397-402). Mendoza: Facultad de Filosofía y Letras, Universidad de Cuyo.

» Saletta, M. J. (2013). Entre viajeros y cronistas. Análisis de la subsistencia, movilidad y tecnología en las fuentes histórico-etnográficas a partir de modelos arqueológicos. Comechingonia Virtual, 7, 46-119.

»Saletta, M. J. (2015). Excavando fuentes: la tecnología, subsistencia, movilidad y los sistemas simbólicos de Shelk’nam, Yámana/Yaghan y Aonikenk entre los siglos XVI y XX analizados a partir de los registros escritos y arqueológicos. (Tesis Doctoral inédita), Universidad de Buenos Aires, Buenos Aires.

»Saletta, M. J. (2017). Los Shelk’nam y los Haush de Tierra del Fuego. En M. Vázquez, D. Elkin y J. Oría (Eds.), Patrimonio a orillas del mar. Arqueología del litoral atlántico de Tierra del Fuego (pp. 103-118). Ushuaia: Editora Cultural Tierra del Fuego.

»Saletta, M. J. y Fiore, D. (2018a). As time goes by. Cantidad de información, visibilidad e intensidad de registro de la tecnología shelk'nam-haush en el registro históricoetnográfico producido por viajeros, misioneros e investigadores en Tierra del Fuego desde el siglo XVI al XX. Revista Electrónica de Fuentes y Archivos, 8, 128-155.

»Saletta, M. J. y Fiore, D. (2018b). Textos y huesos. Análisis comparativo del registro histórico-etnográfico y del registro arqueológico sobre la subsistencia de los shelk'namhaush de tierra del fuego (extremo austral de Sudamérica) entre los siglos dieciséis y veinte. Latin American Antiquity, 29(2), 350-367.

»Saletta, M. J. y Sacchi, M. (2017). Bottled Scrapers, Stone Scrapers: Analysis from 38 sites from SW Patagonia. Trabajo presentado en el 11th International Symposium on Knappable Materials, Buenos Aires y Necochea, Argentina.

»Saletta, M. J. y Sacchi, M. (2019). ¿Ausencias o Abandonos? Las puntas de proyectil en sitios post contacto de Patagonia meridional (siglos XVI al XX). Revista de Estudios Sociales, 67, 101-114.

»Santiago, F., Bujalesky, G. y Salemme, M. (2007). Prospección arqueológica en la cuenca del río Chico. Tierra del fuego, Argentina. En F. Morello, A. Prieto y G. Bahamonde (Eds.), Arqueología de Fuego Patagonia. Levantando piedras, desenterrando huesos... Y develando arcanos (pp. 357-363). Punta Arenas: CEQUA.

"Scheinsohn, V. (1993-1994). Hacia un modelo de aprovechamiento de las materias primas óseas de la Isla Grande de Tierra del Fuego. Relaciones de la Sociedad Argentina de Antropología, XIX, 307-324.

» Schiffer, M. B. (1991). Los procesos de formación del registro arqueológico. Boletín de Antropología Americana, 23, 39-45.

»Senatore, M. X., Buscaglia, S., Bianchi Villelli, M., Marschoff, M., Nuviala, V. y Bosoni, C. (2007). Imágenes de Floridablanca. La construcción material y narrativa de la colonia española (San Julián, siglo XVIII). En F. Morello, A. Prieto y G. Bahamonde (Eds.), Arqueología de Fuego Patagonia. Levantando piedras, desenterrando huesos... Y develando arcanos (pp. 801-812). Punta Arenas: CEQUA. 
» Silliman, S. (2010). Indigenous traces in colonial spaces. Archaeologies of ambiguity, origin, and practice. Journal of Social Archaeology, 10(1), 28-58.

»Vázquez, M., Zangrando, A. F., Tessone, A. y Ceraso, A. (2011). Arqueología de la costa meridional de Península Mitre. En A. F. Zangrando, M. Vázquez y A. Tessone (Eds.), Los cazadores recolectores del extremo oriental fueguino. Arqueología de Península Mitre e Isla de los Estados (pp. 203-230). Bueno Aires: Publicaciones de la Sociedad Argentina de Antropología.

» Vázquez, M., Zangrando, A. F., Tessone, A., Ceraso, A. y Sosa, L. (2007). Arqueología de Bahía Valentín (Península Mitre, Tierra del Fuego): nuevos resultados y perspectivas. En F. Morello, M. Martinic, A. Prieto y G. Bahamonde (Eds.), Arqueología del Fuego Patagonia. Levantando piedras, desenterrando huesos... Y develando arcanos (pp. 755-766). Punta Arenas: CEQUA.

»Vidal, H. (2011). El conocimiento de las culturas aborígenes del sudeste de la Isla Grande hasta 1983. En A. F. Zangrando, M. Vázquez y A. Tessone (Eds.), Los cazadores-recolectores del extremo oriental fueguino. Arqueología de Península Mitre e Isla de los Estados (pp. 65113). Buenos Aires: Publicaciones de la Sociedad Argentina de Antropología.

»Weddell, J. (1825). Un viaje hacia el polo Sur. Realizado en los años 1822-1824 por James Weddell Capitán en la Marina Real. [A voyage towards the South Pole Performed in the years 1822-1824 by James Weddell Master in the Royal Navy.] (E. L. Piana Trans.). Londres: Loneman, Hurst, Rees, Orme, Brown y Green. 